\title{
LA INMUNIDAD DE JURISDICCIÓN PENAL POR CRÍMENES INTERNACIONALES DE LOS JEFES DE ESTADO, LOS JEFES DE GOBIERNO Y LOS MINISTROS DE ASUNTOS EXTERIORES ${ }^{*}$
}

\author{
IMMUNITIES OF HEADS OF STATE, HEADS OF GOVERNMENT \\ AND MINISTERS OF FOREIGN AFFAIRS RELATED TO CRIMINAL \\ JURISDICTION FOR COMMISSION OF INTERNATIONAL CRIMES
}

\author{
Héctor Olasolo Alonso ${ }^{*}$ \\ Juan Ramón MarTínez Vargas ${ }^{* * *}$ \\ Ana María Rodríguez Polanía ${ }^{* * * *}$
}

\begin{abstract}
RESUMEN: El presente artículo tiene como objetivo analizar la evolución del principio de inmunidad del Estado y de sus altos dignatarios desde la perspectiva de la finalidad ético-material de la sociedad internacional y el proceso de humanización de su ordenamiento jurídico. En este sentido, el presente artículo busca realizar una aproximación a las manifestaciones de la inmunidad de los representantes del Estado, centrándose en el aspecto que más ha evolucionado en los últimos años: la inmunidad de jurisdicción penal frente a crímenes internacionales de los Jefes de Estado, el Jefes de Gobierno y Ministros de Asuntos Exteriores.
\end{abstract}

Palabras clave: Inmunidad, Jefes de Estado y Gobierno, Ministros, Derecho Internacional.

ABSTRACT: The objective of this article is to analyze the evolution of the principle of State immunity and of its highest members from a perspective of the ethical and material ends of international society and the humanization process of its legal order and basis. In that sense, this article seeks to approach the different displays of State representatives' immunities, focusing on the issue which has been developed in the most recent years: the criminal immunity of Heads of State, Heads of Government and Foreign Ministers in the context of international crimes.

Key words: Immunity, Heads of State and Government, Ministers, International Law.

\footnotetext{
"Este artículo es producto de la línea de investigación "Derecho internacional desde sus fundamentos filosóficos” del grupo de investigación de Derecho Internacional de la Facultad de Jurisprudencia de la Universidad del Rosario. Bogotá, Colombia.

* Doctor y premio extraordinario de Doctorado por la Universidad de Salamanca (España). Magíster en Derecho por Universidad de Columbia (Nueva York) y Licenciado. En la actualidad es Profesor Principal de Carrera Académica de la Facultad de Jurisprudencia de la Universidad del Rosario. Dirección postal: Calle 12 C No. 6-25, Bogotá. Correo electrónico: hectorolasolo@gmail.com

${ }^{* * *}$ Doctor en Derecho de la Universidad Alfonso X El Sabio (Madrid, España). Magíster en Cuestiones Actuales de Derecho Internacional de la Universidad Alfonso X El Sabio. Abogado de la Universidad del Rosario (Bogotá, Colombia). Profesor Principal de Carrera Académica en Derecho Internacional de la Facultad de Jurisprudencia de la Universidad del Rosario. Dirección postal: Calle 12 C No. 6-25, Bogotá. Correo electrónico: juan.martinez@urosario.edu.co

**** Estudiante de derecho de la Facultad de Jurisprudencia de la Universidad del Rosario. Dirección postal: Calle 12 C No. 6-25, Bogotá. Correo electrónico: rodriguezp.ana@urosario.edu.co
} 


\section{INTRODUCCIÓN}

La reconstrucción del derecho internacional sobre la base del concepto de persona humana supone la alteración esencial de un modelo de ordenamiento jurídico tradicionalmente basado en el concepto de Estado, entendido como forma de organización políticojurídica, caracterizada por el poder de imponer sus mandatos a los sujetos que habitan dentro de un determinado espacio físico, y de desarrollar independientemente sus relaciones con otras entidades jurídico-políticas que respondan a sus mismas características ${ }^{1}$.

La envergadura del cambio es de tal magnitud que el inicio de este proceso solo fue posible cuando el modelo ético material y jurídico formal anterior propició la completa destrucción del continente europeo y de importantes partes de Asia y África, y el recurso al arma más mortífera jamás conocida en la historia: la bomba atómica. Ante esta situación, al término de la II Guerra Mundial se hizo necesario un cambio radical en la praxis de los miembros de la sociedad internacional y en su regulación. Se reconoció con un alcance universal, la naturaleza singular y única del ser humano, de la que emanan ciertos derechos inalienables que todo Estado miembro de la sociedad internacional tiene la obligación de respetar y garantizar².

Simultáneamente, y a la luz de la grave insuficiencia mostrada por las normas que regulaban el comportamiento de las partes en un conflicto armado, se aprobaron en 1949 las cuatro convenciones de Ginebra, cuyo sistema de infracciones graves prevé la responsabilidad internacional penal frente al conjunto de la sociedad internacional de quienes incurran en ellas ${ }^{3}$.

Igualmente, se puso en marcha un mecanismo centralizado de declaración y realización de la responsabilidad internacional penal frente a aquellos dirigentes que con su comportamiento habían generado una guerra de agresión y campañas de violencia sistemática y generalizada contra la población civil. El fracasado intento de enjuiciamiento del káiser Guillermo II de Alemania al término de la Primera Guerra Mundial ${ }^{4}$ dio paso a los proce-

\footnotetext{
1 La Comisión de Arbitraje de la Conferencia de Paz sobre Yugoslavia o Comisión Badinter refiere que "El Estado se define comúnmente como una colectividad que está formada de un territorio y de una población sometidos a un poder político organizado" y "se caracteriza por la soberanía" (Dictamen 1, 29 Nov.1991, RGDIP 1992, p. 264). Para Weber "Si nos preguntamos lo que en la realidad empírica corresponde a la idea del Estado, encontraremos muchas difusas y discretas acciones humanas y reacciones pasivas, vínculos práctica y legalmente ordenados ya sea de carácter singular o de un tipo recurrente regularmente, unidos por una idea que es una creencia en la efectividad de... las normas y en las relaciones de dominación entre las personas". VV.AA. WeBER (1968) pp. 200; KHARKHORDin (2001) pp. 206-240. Harold Laski parte de una definición de Estado conformada por una sociedad integrada por un poder de coerción: "Por Estado, me refiero a una sociedad de esta clase que se integra a través de la posesión de una autoridad coercitiva legalmente suprema sobre cualquier individuo o grupo que forma parte de dicha sociedad. Una sociedad de este tipo es un Estado cuando el estilo de vida que deben conforman estos individuos y asociaciones se define por una autoridad coercitiva vinculante sobre todos ellos. Este poder es denominado soberanía”. LASKI (2008) p. 9.

2 Este reconocimiento se produjo a través de la Declaración Universal de los Derechos Humanos adoptada el 10 de diciembre de 1948, que había sido precedida por la Declaración Americana de los Derechos y Deberes del Hombre (adoptada meses antes), y que sería seguida por el Convenio Europeo para la Protección de los Derechos Humanos y las Libertades Fundamentales de 1950.
}

3 Olasolo (2014a) pp. 8-11 reimpreso en Olasolo (2014c).

4 CRYer et al. (2011) pp. 109-111. 
sos de Núremberg ${ }^{5}$ y Tokio ${ }^{6}$ para juzgar a los dirigentes políticos, militares y económicos de los regímenes alemán y japonés responsables por tales comportamientos. El mensaje era claro: "quienes desde los resortes del poder recurren a una guerra de agresión contra terceros Estados, y utilizan la fuerza armada contra su propia población, no solo pierden la legitimidad ética necesaria para seguir dirigiendo sus respectivas sociedades, sino que, debido al daño que han causado a la sociedad internacional, incurren jurídicamente frente a ella en responsabilidad penal individual" 7 .

Ha sido en este contexto en el que se han desarrollado los deberes de los Estados de no incurrir a través de sus agentes en graves violaciones de derechos humanos (en particular, aquellas constitutivas de crímenes internacionales) frente a quienes se encuentren bajo su jurisdicción, así como a adoptar todas las medidas que estén a su disposición para prevenirlos, y, en caso de que finalmente lleguen a producirse, investigarlos, declarar y realizar la responsabilidad internacional penal derivada de los mismos, y reparar a las víctimas ${ }^{8}$. Correlativamente a estas obligaciones estatales, se han desarrollado también los derechos de estas últimas a la verdad ${ }^{9}$, la justicia ${ }^{10}$ y la reparación ${ }^{11}$.

El proceso de "humanización" del derecho internacional no se ha desarrollado pacíficamente, y se encuentra lejos de haberse completado. Sin embargo, es cierto que el mismo ha permeado las estructuras de la sociedad internacional, y los principios normativos del derecho internacional, de manera que en la actualidad se reconoce la existencia de una dimensión comunitaria en la sociedad internacional, y de normas imperativas o de ius cogens que protegen sus valores esenciales, vinculando a todos sus miembros y privando de eficacia a todo acuerdo o práctica en contrario ${ }^{12}$. Si bien no existe un compendio oficial de normas

\footnotetext{
5 Sentencia del Tribunal Militar Internacional de Núremberg (1946); 1 de octubre de 1946.

6 Sentencia del Tribunal Militar Internacional para el Lejano Oriente (1948); de 4 de noviembre.

7 Olasolo (2014a) p. 9.

8 Sobre concepto de obligaciones de prevención e investigación, véase, Godínez Cruz vs. Honduras (1989): Corte IDH, 20 de enero de 1989. Sobre la inadmisibilidad de la amnistía, de las disposiciones de prescripción y del establecimiento de excluyentes de responsabilidad, respecto de graves atentados contra los derechos fundamentales reconocidos en la Convención Americana, véase, Barrios Altos vs. Perú (2001): Corte IDH, 14 de marzo de 2001.

9 Sobre el derecho a la verdad, véase: ONU. Consejo Económico y Social. Comisión de Derechos Humanos. Conjunto de Principios Actualizado para la Protección y la Promoción de los Derechos Humanos mediante la Lucha contra la Impunidad, E/CN.4/2005/102/Add.1. Principio 2. Frente al derecho a la verdad la CIDH ha establecido que "toda sociedad tiene el derecho inalienable de conocer la verdad de lo ocurrido, así como las razones y circunstancias en las que aberrantes delitos llegaron a cometerse, a fin de evitar que esos hechos vuelvan a ocurrir en el futuro" (CIDH. Informe No 25/98, Chile, Alfonso René Chanfeau Oracye y otros, 7 de abril de 1998. párr 92).

10 Sobre el derecho a la justicia, véase: CIDH. Informe sobre el proceso de desmovilización en Colombia. OEA/Ser.L/V/II.120. Doc. 60. 13 diciembre 2004. Párrafos 34 y 35.

${ }_{11}$ Sobre el derecho a la reparación, véase: CIDH. Informe sobre el proceso de desmovilización en Colombia OEA/Ser.L/V/II.120. Doc. 60. 13 diciembre 2004. Párrafo 43.

${ }^{12}$ El concepto de norma de derecho imperativo o de ius cogens se recoge en el artículo 53 de la Convención de Viena de 1969. Basándose en esta disposición, Lauri Hannikainen, afirma los siguientes cuatro rasgos característicos de las normas de ius cogens: 1 . Se trata de normas de Derecho internacional general; 2 . Tienen que ser aceptadas por la comunidad internacional de Estados en su conjunto; 3. Inderogabilidad; 4. Solo pueden ser modificadas por nuevas normas imperativas. HanniKainen (1988) p. 781. VV.AA. Schwelb (1967) pp. 963; RagAZZi (1997) pp. 58 y ss; Abello (2011) pp. 89-92.
} 
imperativas, existe un cierto grado de consenso en que, cuando menos tiene esta naturaleza las normas relativas a la prohibición del uso de la fuerza, la prohibición del genocidio, la prohibición de la tortura, la prohibición del racismo y el apartheid, el derecho de autodeterminación de los pueblos, y las normas fundamentales del derecho internacional de los derechos humanos y del derecho internacional humanitario ${ }^{13}$.

No son pocos los indicadores que parecen mostrar que el paradigma de la dignidad humana como finalidad ético-material de la sociedad internacional y el proceso de humanización de su ordenamiento jurídico no solo no terminan de consolidarse sino que puede encontrarse en un momento de crisis y franco retroceso.

La verificación de esta afirmación requiere sin duda un estudio mucho más comprensivo del que nos proponemos en el presente trabajo. Sin embargo, creemos adecuado comenzar por una institución que desde mediados del siglo XX se ha convertido en un auténtico caballo de batalla en el desarrollo de dicho proceso: la inmunidad del Estado y de sus representantes. No en vano, en 2012, el juez Cancado Trindade, en su voto particular a la sentencia de la Corte Internacional de Justicia (“CIJ") en el caso sobre las Inmunidades Jurisdiccionales del Estado, expresaba esta situación con toda su crudeza al rechazar las alegaciones de Alemania que afirmaban que el mayor elemento desestabilizador para el ordenamiento jurídico internacional es la aceptación por los tribunales nacionales de las demandas de reparación contra Estados extranjeros presentadas por las víctimas de delitos internacionales de ius cogens ${ }^{14}$. En su opinión, el mayor factor de desestabilización es la propia comisión de tales delitos y no la búsqueda de justicia por las víctimas ${ }^{15}$.

Desarrollaremos nuestra exposición abordando en primer lugar el fundamento y las manifestaciones de la inmunidad del Estado y de sus representantes, para posteriormente centrarnos en el aspecto que más ha evolucionado en los últimos años: la inmunidad de jurisdicción penal frente a crímenes internacionales de los órganos centrales del Estado con competencia en materia de acción exterior (el Jefe de Estado, el Jefe de Gobierno y el Ministro de Asuntos Exteriores) ${ }^{16}$. Finalizaremos, nuestra exposición, con un análisis del significado de la evolución del principio de inmunidad desde la perspectiva de la finalidad ético-material de la sociedad internacional y el mencionado proceso de humanización de su ordenamiento jurídico.

\footnotetext{
13 España v. Belgica (1970): CIJ, 5 de febrero de 1970 (Barcelona Traction, Light and Power Compagny Limited, párr. 33); Nicaragua v. Estados Unidos (1986), CIJ, 27 de junio de 1986 (Actividades militares y paramilitares en y contra Nicaragua, párr. 190); Portugal v. Australia (1996), CIJ, 30 de junio de 1995 (Caso relativo a Timor Oriental, párr. 29). Igualmente, ver: CHETAIL (2003).

Desde una perspectiva normativa, las normas de derecho imperativo o ius cogens cumplen también con la función de dotar de unidad y coherencia a un sistema de derecho internacional.

${ }_{14}$ En nuestro caso las víctimas de crímenes de guerra y lesa humanidad cometidos por las fuerzas armadas alemanas en Italia durante la II Guerra Mundial.

15 Alemania v. Italia (2012): CIJ, 3 de febrero de 2012 (caso sobre Inmunidades Jurisdiccionales del Estado, párr. 129).

16 República Democrática del Congo v. Bélgica (2001): CIJ, 14 de febrero de 2002 (caso sobre la Orden de Arresto de 11 de abril de 2000, párr. 61).
} 


\section{CONCEPTO Y MANIFESTACIONES DE LA INMUNIDAD DEL ESTADO EN CUANTO INSTITUCIÓN}

El principio de inmunidad por el que se impide a un Estado que ejerza jurisdicción sobre otro sin su consentimiento tiene dos manifestaciones: la inmunidad del Estado como institución y la inmunidad de algunos de sus órganos. A pesar de ser dos realidades distintas, puesto que la primera corresponde al ámbito de la responsabilidad estatal, mientras que la segunda pertenece al ámbito de la responsabilidad individual ${ }^{17}$, ambas tienen como fundamento el principio de igualdad soberana de los Estados, y se dirigen a preservar el ejercicio libre e independiente de sus funciones soberanas y la conducción pacífica de las relaciones internacionales ${ }^{18}$.

La inmunidad del Estado es regulada en la actualidad a través de normas consuetudinarias, a la espera de la entrada en vigor del Convenio sobre Inmunidades Jurisdiccionales de los Estados de 2004. Si bien la inmunidad de jurisdicción de la que goza un Estado para sí y para sus bienes, era originalmente absoluta, el Convenio de 2004 refleja que hoy en día se concibe de una manera más restringida sobre la base de una división material entre actos iure gestiones y actos iure imperii ${ }^{19}$. Asimismo, desde principios del siglo XXI surge con autores como Espósito Massini ${ }^{20}$, Focarelli ${ }^{21}$ o Cervell Hortal ${ }^{22}$ una incipiente tendencia a abolir la inmunidad de jurisdicción frente a actos iure imperii que infrinjan normas de ius cogens.

Sin embargo, esta tendencia se encuentra por el momento lejos de cristalizar. Así lo refleja la jurisprudencia de la Corte Europea de Derechos Humanos ("CEDH”) en el caso Al-Adsani c. Reino Unido (2001), en el que rechazó la posibilidad de que los tribunales nacionales del Reino Unido investigaran la responsabilidad civil del Estado de Kuwait por actos de tortura ${ }^{23}$. Del mismo modo, en el caso Karagoleropoulus y otros c. Grecia y Alemania (2002), la propia CEDH afirmó que no se encuentra todavía establecido en Derecho Internacional que los Estados no puedan pretender gozar de inmunidad en caso de acciones civiles por daños-intereses contra la humanidad que se presenten en el territorio de un tercer Estado ${ }^{24}$. No obstante lo anterior, la $\mathrm{CEDH}$ reconoció en este último caso que la actual situación no excluye la posibilidad de que en un futuro, el Derecho internacional consuetudinario se desarrolle en otra dirección ${ }^{25}$.

\footnotetext{
17 Alemania v. Italia (2012): CIJ, 3 de febrero de 2012 (caso sobre Inmunidades Jurisdiccionales del Estado, párr. 91).

18 Cervell (2013) p. 136.

19 Brontons et al. (2010) pp. 569 y ss.

20 Esposito (2007) pp. 323 y ss.

${ }^{21}$ Focarelli (2008) pp. 761-795.

22 Cervell (2013) p. 137.

23 Al-Adsani v. Reino Unido (2002): Corte Europea de Derechos Humanos, 21 de noviembre de 2002, párr. 61-62.

${ }^{24}$ Kalogeropoulos v. Grecia y Alemania (2002): Corte Europea de Derechos Humanos, 12 de diciembre de 2002.

${ }^{25}$ Kalogeropoulos v. Grecia y Alemania (2002): Corte Europea de Derechos Humanos, 12 de diciembre de 2002.
} 
Esta línea jurisprudencial de la CEDH ha sido recientemente ratificada por la CIJ en su sentencia de 3 de febrero de 2012 en el caso sobre las Inmunidades Jurisdiccionales del Estado, en el que Alemania alegó conforme al derecho internacional consuetudinario tener su inmunidad de jurisdicción frente a reclamaciones civiles de particulares ante los tribunales italianos por daños producidos por las fuerzas armadas alemanas durante la II Guerra Mundial. Para la CIJ, "aun de admitir que las acciones intentadas ante las jurisdicciones italianas implicaban violaciones del ius cogens, la aplicación del derecho internacional consuetudinario relativo a la inmunidad de los Estados no resultó afectada" ${ }^{26}$. Esto privaba a las víctimas de la posibilidad de reclamar una indemnización ante los tribunales italianos.

A nivel nacional, los tribunales franceses han adoptado la misma posición que la CIJ afirmando la inmunidad de jurisdicción planteada por Alemania ante las reclamaciones presentadas por particulares por daños ocasionados durante la II Guerra Mundial ${ }^{27}$. Igualmente, los tribunales de Canadá2 ${ }^{2}$, Reino $U_{n i d o}{ }^{29}$, Nueva Zelanda ${ }^{30}$ y Polonia ${ }^{31}$ han acogido la misma posición frente violaciones de ius cogens de terceros Estados. Solamente las decisiones de las Cortes Supremas de Grecia e Italia en los casos Distomo (2000) 32 y Ferrini $(2004)^{33}$ han negado la aplicación de la inmunidad de jurisdicción alegada por Alemania, afirmando que si la comisión de delitos internacionales de ius cogens constituye una excepción al principio de inmunidad en relación con la responsabilidad del individuo, lo mismo debería ocurrir frente a la responsabilidad del Estado.

Se puede afirmar que a pesar de los atisbos de apertura generados por estas dos últimas decisiones nacionales, lo cierto es que tras siete décadas de proceso de humanización del derecho internacional, el tradicional escudo de protección con que el Estado ha contado para no responder ante tribunales nacionales extranjeros por los daños causados por sus actos de iure imperii permanece inalterado, con independencia de los efectos que esto pueda estar generando en el proceso de consolidación de la persona humana como princi-

\footnotetext{
${ }^{26}$ Alemania v. Italia (2012): CIJ, 3 de febrero de 2012 (caso sobre Inmunidades Jurisdiccionales del Estado, con la intervención de Grecia, párr. 91). En este caso Alemania alegó su inmunidad de jurisdicción conforme al derecho internacional consuetudinario frente a reclamaciones civiles de particulares antes los tribunales italianos por daños producidos por las fuerzas armadas alemanas del III Reich durante la II Guerra Mundial.

27 X v. État allemand (2002): Corte de Apelación de Paris, 9 de septiembre de 2002 (AFDI, XLIX, 2003, 724); Bucheron v. RFA (2003): Cour de Cassation, $1^{\text {a }}$ Camara Civil, sentencia de 16 de diciembre de 2003, RGDIP,

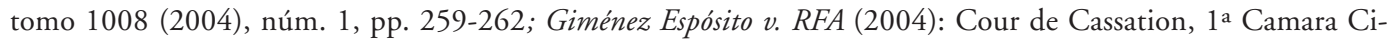
vil, sentencia de 2 de junio de 2004, RCDIPr, núm. 1, enero-marzo 2005, pp. 75-89.

28 Bouzari v. Irán (2002), Tribunal Supremo de Justicia de Ontario,1 de mayo de 2002 (CYIL, XLII (2004), pp. 607-713); Arara v. Jordania (2006), Tribunal Supremo de Justicia de Ontario, de 28 de febrero de 2006.

29 Jones v. Ministerio del Interior Al-Mamlaka Al-Arabiya as Sudiya (2004), Corte de Apelación, 28 de octubre de 2004, (BYIL, LXXV, 2004, pp. 489-504). El caso fue examinado de nuevo por la Cámara de los Lores el 14 de junio de 2006, ver House of Lords, sessions 2005-06 (2006), UKHL 26.

30 Sam Fang and Others v. Zemin Jiang and others (2006), High Court de Nueva Zelanda, 21 de diciembre de 2006.

31 Natoniewski (2010): Corte Suprema de Polonia, en Polish Yearbook of International Law, vol. XXX, 2010, p. 299.

32 Sentencia del Tribunal Supremo Griego, de 4 de mayo de 2000.

33 Sentencia del Tribunal Supremo Italiano, de 11 de mayo de 2001 (RDI, 2004, pp. 539-551).
} 
pio de unidad del ordenamiento jurídico internacional. Para los jueces de la CIJ, Keith y Benouna, esto es resultado de su convencimiento de que es necesario tratar de proteger en la mayor medida posible el principio de soberanía de los Estados ${ }^{34}$.

\section{CONCEPTO Y MANIFESTACIONES DE LA INMUNIDAD DE LOS REPRESENTANTES DEL ESTADO}

La inmunidad de jurisdicción de quienes actúan como agentes de un Estado deriva de la inmunidad del propio Estado al que representan, en tanto que órganos del mismo ${ }^{35}$. $\mathrm{Al}$ ser las funciones principales de este tipo de inmunidad garantizar la efectividad del principio par in parem non habet imperium, y evitar interferencias indebidas por los tribunales extranjeros en los asuntos internos de los Estados mediante el respeto al ejercicio por sus representantes de funciones soberanas, son los propios Estados los que se constituyen en sus beneficiarios reales ${ }^{36}$. En consecuencia, es a estos últimos a los que corresponde exclusivamente la facultad de renunciar a la inmunidad ${ }^{37}$. Con ello se garantiza además el normal desarrollo de las relaciones internacionales ${ }^{38}$.

La evolución en el derecho internacional de las reglas sobre la inmunidad de jurisdicción de los agentes del Estado ha tenido una naturaleza exclusivamente consuetudinaria en relación con los órganos centrales del Estado con competencia en materia de acción exterior $^{39}$. La CIJ en el caso Yerodia (2002) consideró que tales órganos se encuentran conformados por el Jefe de Estado, el Jefe de Gobierno y el Ministro de Relaciones Exteriores ${ }^{40}$. El artículo 3 de la versión más reciente del texto sobre los proyectos de artículo sobre la inmunidad de jurisdicción penal extranjera de los funcionarios del Estado aprobados hasta el momento por la CDI ("Proyecto de Artículos") se refiere también a estos tres altos representantes del Estado al delimitar el grupo de beneficiarios de inmunidad personal ${ }^{41}$.

Sin embargo, la propia CIJ al utilizar en el caso Yerodia la expresión "determinados altos funcionarios como" ${ }^{2}$, parece haber dejado la lista abierta, lo que ha sido utilizado por

34 Véanse las opiniones de los jueces Keith y Benouna en relación con Alemania v. Italia, caso sobre Inmunidades Jurisdiccionales del Estado, CIJ, sentencia de 3 de febrero de 2012.

35 VV.AA. Bassiouni (2003) p. 71; SAtzger (2012) pp. 233-234; AKande (2004) p. 407.

36 Al-Adsani v. Reino Unido (2002), Corte Europea de Derechos Humanos, sentencia de 21 de noviembre de 2002 Párr. 54; Van SchaAK et al. (2010) p. 971. Según la cual: "Es un principio básico del derecho internacional que un Estado soberano no puede juzgar la conducta de otro Estado soberano".

37 BAssiouni (2008), International Criminal Law (Leiden, Editorial M. Nijhoff Pub, tercera edición); CRYER et al. (2011) An Introduction to International Criminal Law (Cambridge, Editorial Cambridge University Press, segunda edición); PAPILLON (2010) p. 279.

38 CRYer et al. (2011) pp. 531 y ss.; AKANDe (2004) pp. 407 y ss.

39 Cervell (2013) p. 534.

40 República Democrática del Congo v. Bélgica (2002), CIJ, 14 de febrero de 2002, párr. 51.

41 La última versión del texto sobre los proyectos de artículo sobre la inmunidad de jurisdicción penal extranjera de los funcionarios del Estado aprobados hasta el momento por la CDI, se encuentra en el Informe de la Comisión de Derecho Internacional sobre su $65^{\circ}$ período de sesiones (6 de mayo a 7 de junio y 8 de julio a 9 de agosto de 2013), Suplemento Núm. 10, A/68/10, 2013, pp. 52-76. Desde 2007 hasta 2011 el Relator del Proyecto fue el Sr. Roman A. Kolodkin. En 2012 fue nombrada como Relatora del Proyecto la Sra. Concepción Escobar.

42 Idem. 
algunos tribunales nacionales para incluir en ocasiones a los ministros de Defensa y Comercio, cuyas actividades pueden tener que desarrollarse en buena medida fuera del territorio nacional ${ }^{43}$. No obstante lo anterior, la CIJ en el caso sobre Ciertas Cuestiones de Asistencia Mutua en Materia Penal (2005), ha puesto límites a esta lista subrayando que el Fiscal General del Estado y el Jefe de la Seguridad Nacional no forman parte de la misma ${ }^{44}$. Debido a la retirada de la demanda, por parte de República del Congo, no pudo sin embargo pronunciarse sobre si el Ministro de Interior se encontraría dentro o fuera de esta lista ${ }^{45}$.

La inmunidad de jurisdicción de los órganos específicos de la Administración Exterior del Estado como las misiones diplomáticas, las oficinas consulares, las misiones especiales y las representaciones permanentes ante Organizaciones o Conferencias internacionales, ha tenido un desarrollo convencional a través del Convenio de Viena sobre Relaciones Diplomáticas (1961), el Convenio sobre Relaciones Consulares (1963), la Convención sobre Misiones Especiales (1969) y el Convenio sobre las representaciones permanentes de los Estados ante las organizaciones internacionales de carácter universal (1975). De ahí, que su régimen jurídico no venga exclusivamente conformado por el derecho internacional consuetudinario.

Ante esta situación, no es de extrañar que desde la aprobación del Convenio sobre Inmunidades Jurisdiccionales de los Estados en 2004, el principal desarrollo en materia de inmunidad se haya producido en relación con el contenido y alcance de la inmunidad de jurisdicción de los Jefes de Estado, los Jefes de Gobierno y los Ministros de Asuntos Exteriores por su presunta responsabilidad en la comisión de crímenes internacionales de ius cogens. En el ámbito civil han sido numerosos los casos, particularmente en EE.UU. a partir del caso Filartiga v. Peña-Irala $(1980)^{46}$, en que se han presentado demandas por crímenes internacionales de ius cogens, sobre todo actos de tortura. Sin embargo, todas aquellas demandas presentadas frente a Jefes de Estado, Jefes de Gobierno y Ministros de Asuntos Exteriores en ejercicio han sido rechazadas, con base en su inmunidad personal ${ }^{47}$.

\footnotetext{
43 Ver a este respecto, las decisiones de los tribunales británicos en relación con las actuaciones frente al Ministro de Defensa israelí en 2004, General Shaul Mofaz, y al Ministro de Comercio chino en 2005 Bo Xilai. Tribunal de Distrito, Re General Shaul Mofaz, sentencia de 12 de febrero de 2004, ICLQ, vol. 53, 2004, pp. 773; y Re Bo Xilai, Tribunal de Magistrados de Bow Street, sentencia de 8 de noviembre de 2005, en ILR, vol. 128, p. 714.

44 Djibuti v. Francia (2008) CIJ, 4 de junio de 2008 (Caso sobre Ciertas Cuestiones de Asistencia Mutua en Materia Penal, párr. 194).

45 El caso se inicio en 2002 a raíz de que un juez del Tribunal de Gran Instancia de Meaux inició una investigación por crímenes de lesa humanidad y crímenes de guerra contra, entre otros, el entonces Presidente de la República de Congo, Denis Sssou Nguesso y el Ministro de Interior en ejercicio, General Pierre Oba.

46 En este caso, dos ciudadanos paraguayos presentaron ante un tribunal federal de EE.UU. una demanda conforme al Alien Tort Statute, solicitando una indemnización al antiguo jefe de policía de Paraguay que había torturado y asesinado a uno de sus familiares. Si bien en primera instancia se rechazó su petición por falta de jurisdicción, esta fue aceptada en segunda instancia.

47 En su último informe, la Comisión de Derecho Internacional se refiere a título de ejemplo a los siguientes casos en los que se ha reconocido la inmunidad de jurisdicción ratione personae de los Jefes de Estado: Kline $v$. Kaneko (1988); Corte Suprema del Estado de Nueva York, sentencia de 31 de octubre de 1988 (141 Misc. 2d 787); Mobutu v. SA Cotoni, (1988); Tribunal civil de Bruselas, sentencia de 29 de diciembre de 1988; Ferdinand et Imelda Marcos v. Office fédéral de la pólice (1989); Tribunal Federal (Suiza), sentencia de 2 de noviembre de 1989; Lafontant v. Aristide (1994); Tribunal de Distrito, Distrito Este de Nueva York (Estados Unidos), sentencia de 27 de enero de 1994; W. v. Prince of Liechtenstein (2001); Tribunal Supremo (Austria), sentencia de 14
} 
Pero sin duda que los principales desarrollos se han producido en materia de inmunidad de jurisdicción penal tanto frente a tribunales nacionales extranjeros como frente a tribunales internacionales penales, lo que ha ocasionado que la Comisión de Derecho Internacional se encuentre preparando desde 2007 un comprensivo Proyecto de Artículos sobre la inmunidad de jurisdicción penal frente a los primeros ${ }^{48}$. Por su parte, el Instituto de Derecho Internacional (IDI) ha aprobado sendas resoluciones en sus sesiones de Vancouver (2001) y Nápoles (2009) incluyendo también a los tribunales internacionales penales.

El desarrollo del contenido y alcance de la inmunidad de jurisdicción penal de los Jefes de Estado, los Jefes de Gobierno y los Ministros de Asuntos Exteriores se ha debido a tres factores principales. En primer lugar, es un hecho constatado que los crímenes internacionales de ius cogens son normalmente cometidos con el apoyo o consentimiento de los Estados ${ }^{49}$. En segundo lugar, la implementación del principio del jurisdicción universal a nivel nacional ha permitido la presentación, desde el caso Pinochet a finales de los años noventa, de decenas de querellas en tribunales extranjeros contra altos representantes de los Estados, incluyendo los siguientes Jefes de Estado: Eric Honecker de la República Democrática Alemana (en la República Federal de Alemania), Muammar Gaddaffi de Libia (en Francia), Hassan II de Marruecos (en España), Fidel Castro de Cuba (en España), Paul Kagame de Ruanda (en España), Hugo Chávez de Venezuela (en España), Augusto Pinochet de Chile (en España), y Jiang Zemin de China (en Argentina y España). En tercer lugar, numerosos altos representantes de los Estados han sido enjuiciados en tribunales internacionales penales, incluyendo los siguientes Jefes de Estado: Slobodan Milosevic en el Tribunal Internacional Penal para la ex Yugoslavia, (“TPIY”), Charles Taylor en la Corte Especial para Sierra Leona, (“CESL”), Khieu Samphan en las Salas Especiales de las Cortes de Cambodia, (“SECC”) y Omar Al Bashir, Muammar Gaddafi, Laurent Ngagbo y Urumu Kenyatta en la Corte Penal Internacional, (“CPI”).

Sobre la base de la tradicional distinción entre inmunidad personal o ratione personae e inmunidad funcional o ratione materiae, estudiaremos el tratamiento que se ha dado a esta cuestión dependiendo de si se pretende declarar su responsabilidad internacional penal ante tribunales nacionales extranjeros o ante tribunales internacionales penales. Con ello abordaremos los dos modelos existentes (directo o centralizado, e indirecto o descentralizado) para la aplicación del derecho internacional penal, cuya eficacia es complementaria

de febrero de 2001 (7 Ob 316/00x); Tachiona v. Mugabe (“Tachiona I") (2001), Tribunal de Distrito de Nueva York (Estados Unidos), sentencia de 30 de octubre de 2001 (169 F. Supp. 2d 259); Fotso v. Republic of Cameroon (2013), Tribunal de Distrito de Oregón (Estados Unidos), sentencia de 22 de febrero de 2013 (6:12CV 1415-TC). Vid. Informe de la Comisión de Derecho Internacional sobre su $65^{\circ}$ período de sesiones (6 de mayo a 7 de junio y 8 de julio a 9 de agosto de 2013), Suplemento Núm. 10, A/68/10, 2013, p. 63, nota al pie 267.

48 Véase el Informe de la Comisión de Derecho Internacional sobre su $65^{\circ}$ período de sesiones (6 de mayo a 7 de junio y 8 de julio a 9 de agosto de 2013), Suplemento Núm. 10, A/68/10, 2013, pp. 52-76.

49 El propio artículo 1 de la Convención contra la Tortura de 1984 refleja esta situación al exigir como requisito para la constitución de un acto de tortura que “(...) dichos dolores o sufrimientos sean infligidos por un funcionario público u otra persona en el ejercicio de funciones públicas, a instigación suya o con su consentimiento o aquiescencia.(...)". Del mismo modo, el artículo 7(2) del ECPI afirma que para la existencia de un crimen contra la humanidad es necesario que los actos de violencia contra la población civil se desarrollen en ejecución de la política de un Estado o de una organización. 
a la hora de proteger los bienes jurídicos tutelados por los crímenes internacionales de ius cogens $^{50}$.

\section{LA INMUNIDAD DE LOS JEFES DE ESTADO, JEFES DE GOBIERNO Y MINISTROS DE ASUNTOS EXTERIORES FRENTE A LAS ACTUACIONES PENALES DE LOS TRIBUNALES NACIONALES EXTRANJEROS}

\section{A. InMunidad Personal}

El derecho internacional consuetudinario distingue entre inmunidad personal e inmunidad funcional ${ }^{51}$. La primera, conocida como inmunidad personal o ratione personae, otorga protección frente a los tribunales nacionales extranjeros en relación con todos los actos tanto de carácter oficial como de naturaleza privada ${ }^{52}$ realizados durante el desempeño del cargo, o con anterioridad al mismo ${ }^{53}$. De esta manera, la inmunidad personal asegura la plena inviolabilidad del Jefe de Estado, el Jefe de Gobierno y el Ministro de Asuntos Exteriores para que puedan desempeñar sus funciones sin interferencias de ningún tipo ${ }^{54}$, garantizando con ello la conducción pacífica de las relaciones internacionales ${ }^{55}$.

La protección ofrecida por la inmunidad personal se extiende a todos los actos de los tribunales nacionales extranjeros que puedan impedir al Jefe de Estado, Jefe de Gobierno y Ministro de Asuntos Exteriores el desarrollo efectivo de sus funciones. Esto se produce cuando, como en el caso Yerodia (2002) ante la CIJ, un Ministro de Relaciones Exteriores es arrestado en otro Estado para enfrentar una acusación penal ${ }^{56}$. Sin embargo, la propia CIJ ha subrayado que la protección no se extiende a aquellas actuaciones de los tribunales nacionales extranjeros que no afecten al desempeño de las funciones. Esta fue precisamente la situación que se planteó en el caso sobre Ciertas Cuestiones de Asistencia Mutua en Asuntos Penales (2008), en el que un tribunal francés envió una notificación invitando a testificar al Presidente de la República de Djibuti en relación con la muerte de uno de sus asesores, dejando en última instancia a aquel en libertad para aceptar o declinar la invitación ${ }^{57}$.

\footnotetext{
${ }^{50}$ Bassiouni, distingue entre un modelo de aplicación directa del derecho internacional penal a través de un órgano jurisdiccional internacional, y un modelo de aplicación indirecta a través de los órganos jurisdiccionales nacionales. Ambos modelos de aplicación podrían ser en su opinión efectivos en la lucha para proteger los bienes jurídicos tutelados por los crímenes internacionales. VV.AA (BASSIOUnI, (1980), pp. 107 y ss; Olasolo (2003)

51 VV.AA. Werle (2011) pp. 383; Cryer et al. (2011) pp. 533; AKande (2011) pp. 817; Van Alebeek (2008) pp. 158 y ss. PAPILlon (2010) p. 278; CASSENE (2008) p. 302. La CIJ también reconoció la existencia de esta clasificación de las inmunidades en el "caso sobre ciertas cuestiones de asistencia mutua en materia penal". Djibouti v. France (2008) CIJ , 4 de junio de 2008, (Caso sobre Ciertas Cuestiones de Asistencia Mutua en Materia Penal).

52 A/CN.4/654, informe preliminar sobre la inmunidad de jurisdicción penal extranjera de los funcionarios del Estado, 31 de mayo de 2012. p. 16

53 A/66/10, Comisión de derecho Internacional, $63^{\circ}$ periodo de sesiones, pp. 235.

54 CAHIER (1965) p. 261.

55 AKANDE et al. (2011) p. 818.

56 República Democrática del Congo v. Bélgica (2002), CIJ, 14 de febrero de 2002 (caso sobre la Orden de Arresto de 11 de abril de 2000, párr. 55).

57 Djibouti v. France (2008) CIJ, 4 de junio de 2008, (Caso sobre Ciertas Cuestiones de Asistencia Mutua en Materia Penal, párrs. 169 y 170).
} 
La inmunidad personal tiene un carácter temporal, porque cesa en el momento en que se deja de desempeñar el cargo, de ahí su configuración como un obstáculo de naturaleza exclusivamente procesal al ejercicio de la jurisdicción penal ${ }^{58}$. Esto significa también que, una vez dejado el cargo, un Jefe del Estado, un Jefe de Gobierno o un Ministro de Asuntos Exteriores puede ser enjuiciado por un tribunal nacional extranjero por todo delito cometido antes o durante el desempeño del mismo, siempre y cuando no se encuentre amparado por la inmunidad funcional que protege los actos de carácter oficial ${ }^{59}$.

El carácter absoluto de la inmunidad personal hace que no pueda ser objeto de excepción con base en la seriedad del delito cometido ${ }^{60}$. Sin embargo, no existiendo controversia sobre esta regla en relación con los delitos ordinarios, surge la pregunta sobre su aplicación con respecto a los delitos internacionales de ius cogens. En otras palabas, ¿pueden los tribunales nacionales extranjeros entrar a juzgar a Jefes de Estado, Jefes de Gobierno o Ministros de Relaciones Exteriores en ejercicio, cuando se trata de aquellos delitos que afectan más gravemente a la dignidad humana como criterio de unidad del ordenamiento jurídico internacional?

Para autores como Ambos, el mero planteamiento de esta pregunta ya resulta en sí problemático ante la dificultad de especificar cuáles son aquellos crímenes internacionales que han sido prohibidos por normas de ius cogens ${ }^{61}$. Sin embargo, lo cierto es que existe un amplio consenso sobre el hecho de que, al menos, el de genocidio, los delitos centrales del fenómeno de la lesa humanidad, las infracciones graves a los cuatro Convenios de Ginebra de 1949, y la tortura entrarían en esta categoría ${ }^{62}$.

Con anterioridad al año 2002, varios tribunales nacionales en Alemania, España y Francia habían rechazado los casos por crímenes internacionales de ius cogens contra Eric Honecker $(1984)^{63}$, Hassan II (1998) ${ }^{64}$, Fidel Castro (1999) ${ }^{65}$ y Muammar Gaddafi $(2001)^{66}$-todos ellos Jefes de Estado en ejercicio al abrirse las actuaciones penales- debido a su inmunidad personal.

58 WeRLE (2011) p. 384.

59 República Democrática del Congo v. Bélgica (2002), CIJ, 14 de febrero de 2002 (caso sobre la Orden de Arresto de 11 de abril de 2000, párr. 55).

${ }^{60}$ CRYer et al. (2011) p. 533.

República Democrática del Congo v. Bélgica (2002), CIJ, 14 de febrero de 2002, (caso sobre la Orden de Arresto de 11 de abril de 2002, párr. 59).

${ }^{61}$ Ambos (2013) p. 413.

${ }^{62}$ Bassiouni (2011) p. 174. Sobre el carácter de ius cogens del núcleo central de los crímenes de lesa humanidad, véase Olasolo (2014a) pp. 45-49; reimpreso en Olasolo (2014c).

63 Re Honecker (1984); Tribunal Supremo Federal, Segunda Sala de lo Penal (República Federal de Alemania), sentencia de 14 de diciembre de 1984 (causa No 2 ARs 252/84) reproducida en International Law Reports, vol. 80, pp. 365 y 366 ;

64 Auto de la Sala Penal de la Audiencia Nacional de España, de 23 de diciembre de 1998.

65 Ver, auto de la Sala Penal de la Audiencia Nacional de España, de 4 de marzo de 1999. En auto de 13 de diciembre de 2007, la Sala Penal de la Audiencia Nacional de España volvía a pronunciase en el mismo sentido ante la presentación de una nueva querella contra Fidel Castro.

${ }^{66}$ Kadhafi (2001); Tribunal de Casación, Sala de lo Penal (Francia), sentencia No 1414, de 13 de marzo de 2001, reproducida en Revue générale de droit international public, vol. 105 (2001), pág. 474; versión inglesa reproducida en International Law Reports, vol. 125, pp. 508 a 510. Para mayor información, ZAPpala (2001). 
Esta línea jurisprudencial ha sido confirmada por la sentencia de la CIJ de 14 de febrero de 2002 en el caso Yerodia, en el que la República Democrática del Congo demandó a Bélgica por haber violado la normativa internacional sobre inmunidad personal al dictar un juez belga una orden de arresto contra su entonces Ministro de Relaciones Exteriores por su presunta responsabilidad en la comisión de crímenes de lesa humanidad y de guerra. Para la CIJ, así como la gravedad del delito no afecta al contenido de la inmunidad personal, esta tampoco se ve afectada porque los crímenes imputados hayan sido prohibidos por una norma de ius cogens ${ }^{67}$.

Con posterioridad a esta sentencia, se han adoptado nuevas decisiones a nivel nacional cerrando los procedimientos penales abiertos contra los Jefes de Estado en ejercicio Paul Kagame $(2006)^{68}$ y Fidel Castro $(2007)^{69}$ en aplicación de su inmunidad personal. La exclusión de toda excepción por razón de la naturaleza de ius cogens de los crímenes internacionales imputados, también parece ser la posición asumida por la CDI en la última versión de su Proyecto de Artículos ${ }^{70}$. Igualmente, el IDI, en los artículo 13 y II de sus resoluciones de 2001 y 2009 ha acogido esta misma posición.

En consecuencia, se puede concluir que desde la finalización de la II Guerra Mundial no se ha producido ni la más mínima grieta en la inviolabilidad proporcionada por la inmunidad personal a los Jefes de Estado, Jefes de Gobierno y Ministros de Asuntos Exteriores en ejercicio. Con ello, se prima la igualdad soberana de los Estados, la preservación del ejercicio de sus funciones por sus más altos representantes y la conducción pacífica de las relaciones internacionales. Al mismo tiempo, se relega a un segundo plano el interés de la sociedad internacional en recurrir a su sistema descentralizado (a través de las jurisdicciones nacionales) de aplicación del derecho internacional penal, para garantizar la investigación y el enjuiciamiento de los máximos responsables de aquellos crímenes internacionales que afecta gravemente a la persona humana como criterio de unidad del ordenamiento jurídico internacional.

\section{B. INMUNIDAD FUNCIONAL}

El derecho internacional consuetudinario reconoce un segundo tipo de inmunidad, denominada funcional o ratione materiae, que cubre los actos llevados a cabo con carácter oficial y en nombre del Estado que se representa ${ }^{71}$. Se define por la naturaleza de los actos

\footnotetext{
${ }_{67}$ República Democrática del Congo v. Bélgica (2002), CIJ, 14 de febrero de 2002 (caso sobre la Orden de Arresto de 11 de abril de 2002, párr. 58). Véase también DAmGAARD (2008) p. 263. La CIJ no entró a valorar en el caso Yerodia el alcance de la inmunidad personal del personal diplomático, prevista en la Convención de Viena sobre Relaciones Diplomáticas de 1961, en relación con delitos de ius cogens

68 Auto del Juzgado núm. 4 de la Audiencia Nacional de España, de 6 de febrero de 2008.

69 Auto de la Sala Penal de la Audiencia Nacional de España, de 13 de diciembre de 2007.

70 Véase la última versión del Proyecto de Artículos en el Informe de la Comisión de Derecho Internacional sobre su $65^{\circ}$ período de sesiones ( 6 de mayo a 7 de junio y 8 de julio a 9 de agosto de 2013), Suplemento Núm. 10, A/68/10, 2013, pp. 71-75.

71 AKANDEE et al. (2011) p. 826.
} 
realizados, y no por la condición personal de los agentes estatales que los llevan a cabo ${ }^{72}$. Tiene una naturaleza parcial puesto que solo cubre los actos de carácter oficial, y por tanto no se extiende a los actos privados. Además, debido a que la inmunidad funcional se encuentra ligada al acto oficial y no a la persona, no tiene límite temporal, permaneciendo aún después de que se haya dejado el cargo ${ }^{73}$.

Algunos autores como Cassese ${ }^{74}$, Werle ${ }^{75}$, Akande y Shah ${ }^{76}$ han afirmado la naturaleza sustantiva de este tipo de inmunidad porque, en su opinión, los actos que son propios del Estado no pueden ser atribuibles al agente estatal que los realiza. En consecuencia, su intervención en los mismos no le genera responsabilidad internacional penal.

Sin embargo, esta posición ha sido rechazada por autores como Ambos $^{77}$ y Cryer $^{78}$, al afirmar que no solo no es necesario reconocer a la inmunidad funcional una naturaleza sustantiva para que sea efectiva, sino que además las consecuencias de afirmar tal naturaleza son inaceptables. Para estos autores, si el autor del delito no es penalmente responsable porque el hecho punible no le es atribuible al ser un acto del Estado, tampoco las terceras personas que hayan participado a título de partícipes incurrirán en responsabilidad, puesto que la responsabilidad de partícipe es dependiente de la responsabilidad del autor ${ }^{79}$. En consecuencia, afirmar la naturaleza sustantiva de la inmunidad funcional supone excluir la responsabilidad penal de todos aquellos partícipes (ya sean o no agentes del estado) que actúen sin encontrarse protegidos por algún tipo de inmunidad ${ }^{80}$.

Esta última circunstancia resulta a nuestro parecer decisiva, en cuanto que acoger la naturaleza sustantiva de la inmunidad funcional supondría su injustificada extensión por vía indirecta. Además, de no aceptarse su configuración como un obstáculo procesal, su mera invocación exigiría entrar a realizar juicios de valor sobre la antijuridicidad y la culpabilidad de la conducta del agente estatal. Es por ello reseñable que la CIJ en sus sentencias en el caso Ye-

72 La enunciación de esta doctrina, que tiene su fundamento en la Doctrina del Acto de Estado, se encuentra en al artículo 4 del Proyecto de Artículos de la Comisión de Derecho Internacional sobre la Responsabilidad del Estado por Hechos Internacionalmente Ilícitos (2003). En dicha disposición se establece que "se considerará hecho del Estado según el derecho internacional el comportamiento de todo órgano del Estado, ya sea que ejerza funciones legislativas, ejecutivas, judiciales o de otra índole, cualquiera que sea su posición en la organización del Estado y tanto si pertenece al gobierno central como a una división territorial del Estado".

73 VV.AA. SATZger (2012) p. 234; CASSESE (2008) p. 304.

74 CASSESE (2008) p. 253. En el mismo sentido, el TPIY en el caso Blaškić ha afirmado que "State officials are mere instruments of a State and their official action can only be attributed to the State. They cannot be the subject of sanctions or penalties for conduct that is not private but undertaken on behalf of the State. In other words, State officials cannot suffer the consequences of wrongful acts which are not attributable to them personally but to the State on whose behalf they act: they enjoy the so-called "functional immunity". This is a well established rule of customary international law going back to the eighteenth and nineteenth centuries, restated many times since”. TPIY, Fiscal v. Blaškic (1997); TPIY, Sala de Apelaciones, Fallo sobre la Solicitud de Croacia para la revisión de la decisión de la Sala de Juicio II del 18 de julio de 1997, fallo del 29 de octubre de 1997. Párr. 38.

75 Werle (2011) pp. 383 y 384.

76 AKANDE et al. (2011) p. 304.

77 Ambos (2013) p. 410.

78 CrYer et al. (2011) p. 534; Al-Adsani v. Reino Unido (2002), Corte Europea de Derechos Humanos, 21 de noviembre de 2002, Párr. 48.

79 Ambos (2013) p. 411.

80 Ambos (2013) p. 411. 
rodia y en el caso sobre Inmunidades Jurisdiccionales del Estado haya rechazado la naturaleza sustantiva de la inmunidad funcional al afirmar que la inmunidad (con independencia de que sea personal o funcional) y la responsabilidad internacional penal son dos conceptos notablemente distintos, debido a la naturaleza procesal de la primera ${ }^{81}$.

La aplicación ante tribunales nacionales extranjeros de la inmunidad funcional por crímenes internacionales de ius cogens, es ciertamente más controvertida que en el caso de la inmunidad personal. Por una parte, como Cassese ha señalado, existen numerosos tribunales nacionales que han negado la aplicación de la inmunidad funcional de agentes estatales extranjeros cuando de crímenes internacionales de ius cogens se ha tratado ${ }^{82}$. Esta es la situación en los casos Eichman en Israel ${ }^{83}$, Barbie en Francia, Kappler y Priebke en Italia, Rauter, Albrecht y Bouterse en Paises Bajos, Kesserling ante una corte militar británica en Italia, Von Lewinski ante una corte militar británica en Hamburgo, Pinochet en España y el Reino Unido, Yamashita en los Estados Unidos, Buhler en Polonia y Miguel Cavallo en Mexico.

En el mismo sentido, la temprana jurisprudencia del Tribunal Internacional Penal para la ex Yugoslavia en los casos Blaskic, Furundzija, Karadzic y Milosevic ha afirmado también la improcedencia frente a tribunales nacionales extranjeros de la inmunidad funcional por crímenes internacionales ${ }^{84}$.

Esta misma posición ha sido sostenida por el IDI en sus resoluciones de $2001 \mathrm{y}$ 2009 al afirmar que "aparte de la inmunidad personal de la que se beneficia un individuo en virtud del Derecho internacional, ninguna inmunidad se aplica al caso de crímenes internacionales" ${ }^{85}$. Del mismo modo, la Asociación de Derecho Internacional, en su conclusión $4^{\mathrm{a}}$ del informe de 2000 sobre "el ejercicio de la jurisdicción universal respecto de

${ }^{81}$ República Democrática del Congo v. Bélgica (2002), CIJ, 14 de febrero de 2002 (caso sobre la Orden de Arresto de 11 de abril de 2000, párr. 60); Alemania v. Italia (2012), CIJ, 3 de febrero de 2012 (Caso sobre Inmunidades Jurisdiccionales del Estado con la intervención de Grecia, párr. 93).

82 CASSESE (2008) p. 305. Con base en esta amplia práctica a nivel nacional, Cassese afirma la existencia de una costumbre internacional cuya opinio iuris se habría originado con las resoluciones de la Asamblea General de las Naciones Unidas 95(I) de 1946, 177 (II) de 21 de noviembre de 1947 y 488(V) de 12 de diciembre de 1950, así como con el proyecto de código de crímenes internacionales presentado por la Comisión de Derecho Internacional en 1950, que reafirman el principio de improcedencia del cargo oficial previsto en el artículo 7 del Acuerdo de Londres de 1945.

83 En el caso Eichman, la defensa argumentó que las acciones realizadas hacían parte de sus funciones oficiales y eran un acto de Estado ("act of State”). Sin embargo, tanto el Tribunal de Distrito de Jerusalén en su sentencia de 12 de diciembre de 1961 (párrafo 28), como el propio Tribunal Supremo de Israel en su sentencia de 29 de mayo de 1962 (párrafo 14), afirmaron que los agentes estatales no se encuentran cubiertos por la inmunidad funcional frente a responsabilidad penal en caso de cometer crímenes internacionales.

84 Véase, Fiscal v. Blaškić (1997); TPIY, sala de Apelaciones, Fallo sobre la Solicitud de Croacia para la revisión de la decisión de la Sala de Juicio II del 18 de julio de 1997, fallo del 29 de octubre de 1997, párr. 41.

85 Apartado 1 del artículo II de su resolución de 2009. Por su parte, en el artículo 13 de su anterior resolución sobre esta cuestión de 2001 se afirmaba que " 1 . El Jefe de Estado que ya no se encuentre en funciones no se beneficia de ninguna inviolabilidad en el territorio de un Estado extranjero. 2. Tampoco se beneficia de ninguna inmunidad de jurisdicción tanto en materia penal como en materia civil o administrativa, salvo que se refiere a actos llevados a cabo en el ejercicio de sus funciones y relacionados con el cargo. Sin embargo, puede ser perseguido y juzgado cuando los actos alegados constituyan un crimen bajo el Derecho internacional o cuando se lleven a cabo con el fin exclusivo de satisfacer intereses personales o constituyan una apropiación fraudulenta de bienes o recursos del Estado". 
violaciones graves de Derechos Humanos", ha subrayado que "ninguna inmunidad respecto de lesiones graves de derechos humanos sujetas a jurisdicción universal se aplicará en caso de que los crímenes se llevaran a cabo en el ejercicio de potestades oficiales".

Sin embargo, en 2002, la CIJ en el caso Yerodia adoptaba la posición contraria al afirmar que la norma consuetudinaria sobre inmunidad funcional no estaba sujeta a ninguna excepción por razón de ius cogens de los crímenes internacionales imputados. En consecuencia, subrayaba la CIJ, la inmunidad funcional es aplicable incluso en aquellos casos en los que un Jefe de Estado, un Jefe de Gobierno o un Ministro de Relaciones Exteriores haya cesado en su cargo, y por lo tanto no podrá ser enjuiciado ante un tribunal de un país extranjero a menos que se trate de actos de naturaleza privada ${ }^{86}$.

Sobre esta base, la cumbre de expertos de la Unión Africana y la Unión Europea y que tuvo lugar en 2009 sobre el principio de jurisdicción universal concluyó afirmando que "aquellas autoridades nacionales de justicia penal que consideren el ejercicio de la jurisdicción universal sobre personas sospechosas de graves crímenes de ámbito internacional están jurídicamente obligadas a tener en cuenta todas las inmunidades que poseen los agentes estatales y deben, por tanto, abstenerse de enjuiciarles" 87 .

Con posterioridad, el último debate sostenido sobre esta cuestión en 2011 en el seno de la CDI ha mostrado que las posiciones se encuentran completamente divididas entre (i) quienes abogaban por la existencia de un norma consuetudinaria que no admite excepciones a la inmunidad funcional, pues de lo contrario se podría "socavar el fundamento de las relaciones internacionales, inducir a la formulación de acusaciones basadas en motivos políticos y plantear dudas en cuanto al respeto de las garantías procesales" y (ii) quienes afirmaban la cristalización de una excepción consuetudinaria a dicha norma que haría inaplicable la inmunidad funcional en caso de crímenes internacionales de ius cogens ${ }^{88}$.

Ante esta situación, no es posible afirmar en este momento que la tendencia observada en la práctica internacional hacia el establecimiento de una excepción consuetudinaria a la inmunidad funcional con respecto a crímenes internacionales haya cristalizado. Por el contrario, parece que nos encontremos más bien en un punto muerto, donde lo divisiones son ostensibles.

Lo mismo acontece en relación con los varios argumentos que se han utilizado para justificar la mencionada excepción. Así, en primer lugar, se ha afirmado que la comisión de este tipo de crímenes no puede ser nunca parte de las funciones oficiales del cargo. Este argumento fue acogido por los varios de los magistrados de la Cámara de los Lores ${ }^{89}$, máxima instancia judicial de Inglaterra, que dictó la sentencia de 24 de marzo de 1999 en el caso

86 República Democrática del Congo v. Bélgica (2002), CIJ, 14 de febrero de 2002 (caso sobre la Orden de Arresto de 11 de abril de 2000, párr. 61).

87 Report of the Technical ad hoc African Union-Europea Union Expert Group on the Principle of Universal Jurisdiction, Consejo de la Unión Europea, Doc. Núm. 8672/1/09 Rev. 1, 16 de abril de 2009, p. 42.

88 Véase el Informe del Relator Kolodkin en la 63ª sesión de la CDI en ILC Report, A/66/10, 2011, párrs. 141-203.

89 Véanse las opiniones de Lord Steyn, Lord Nicholls of Birkenhead, Lord Hutton y Lord Phillips of Worth Matravers, en R. v. Bow Street Stipendiary Magistrate and others, ex parte Pinochet (No. 3), 1999. 
contra el ex Jefe de Estado de Chile Augusto Pinochet ${ }^{90}$. También ha sido sostenido por los jueces Higgings, Kooijmans y Buergenthal en su voto particular a la sentencia de la CIJ en el caso Yerodia ${ }^{91}$. Además, algunos autores como Bianchi han defendido esta posición sobre la base de que el derecho internacional no puede considerar como actos soberanos aquellos no solo son una violación del propio derecho internacional, sino que constituyen un ataque contra su fundamento y valores constitutivos ${ }^{92}$.

Sin embargo, este argumento plantea varios problemas. En primer lugar, tal y como Akande y Shah señalan, el carácter oficial de un acto no puede depender de que constituya o no un crimen internacional, ni tan siquiera de su legalidad o ilegalidad, sino del propósito y los medios mediante los cuales los agentes estatales lo llevaron a cabo ${ }^{93}$. En segundo lugar, el argumento no se corresponde con el hecho constatado de que los crímenes internacionales de ius cogens son normalmente cometidos con el apoyo o consentimiento de los Estados, lo que supone la intervención por acción u omisión de sus fuerzas policiales, militares o de inteligencia ${ }^{94}$.

En tercer lugar, como Cassese ha señalado, es la capacidad que atribuye el cargo de agentes estatales, particularmente en el caso de los Jefes de Estado, los Jefes de Gobierno y los Ministros de Relaciones Exteriores, lo que les coloca en situación de ordenar, instigar, asistir o tolerar la comisión de crímenes internacionales ${ }^{95}$. En consecuencia, si no abusaran de las facultades que les atribuye su cargo oficial, no tendrían ni la capacidad ni los medios para llevarlos a cabo.

Finalmente, tal y como afirma Ambos, si se aceptara que ningún crimen internacional pudiera ser cometido como parte de las funciones oficiales, entonces todos ellos tendrían que ser considerados como actos privados, y no podrían ser tampoco atribuidos al Estado en cuyo nombre actuaron los agentes estatales ${ }^{96}$. En consecuencia, el Estado no sería responsable, ni tendría que proceder a la reparación integral de las víctimas.

Ante esta situación, autores como Bianchi han recurrido a un segundo argumento para afirmar la inexistencia de inmunidad funcional ante tribunales nacionales extranjeros por crímenes internacionales de ius cogens. Conforme al mismo, al recogerse la prohibición de incurrir en tales crímenes en normas internacionales del máximo rango jerárquico, estas, desde una perspectiva normativa, deberían prevalecer sobre aquellas otras normas de derecho internacional que tienen un rango inferior como es el caso de la norma consuetudinaria en la que se establece la inmunidad funcional ${ }^{197}$. En definitiva, como Cervell Hortal se pregunta, "si la norma de ius cogens es la aceptada y reconocida por la comunidad internacional de Estados en su conjunto como que no admite acuerdo en contrario y que solo puede modificarse por una

\footnotetext{
90 R. v. Bow Street Stipendiary Magistrate and others, ex parte Pinochet (No 3), 1999, P. 113 y 116.

${ }^{1}$ República Democrática del Congo v. Bélgica (2002); CIJ, 14 de febrero de 2002, (caso sobre la Orden de Arresto de 11 de abril de 2000, párr. 85).

92 Bianchi (1999) p. 237.

93 AKAnde et al. (2011) p. 832.

94 Cryer et al. (2011) p. 540.Véase a este respecto el artículo de 1 de la Convención contra la Tortura de 1984, y el artículo 7(2) del Estatuto de la Corte Penal Internacional.

95 CASSESE (2002) p. 868.

96 Ambos (2013) p. 412

97 Bianchi (1999) pp. 262 y 265.
} 
norma ulterior del mismo carácter, si son normas que por su propia naturaleza deben primar sobre las demás y obligarlas por tanto a retroceder, ¿por qué no habrían de prevalecer entonces incluso la inmunidad de jurisdicción, que no tiene ese carácter?"98.

Sin embargo, este segundo argumento tampoco se encuentra exento de problemas tal y como han apuntado Cryer ${ }^{99}$, Ambos ${ }^{100}$, Hazel Fox ${ }^{101}$, Akande y Shah ${ }^{102}$. Estos autores subrayan que, mientras las normas de ius cogens que prohíben los crímenes internacionales y hacen nacer la responsabilidad internacional penal operan en un plano sustantivo, las normas convencionales y consuetudinarias que reconocen la inmunidad funcional operan en un ámbito estrictamente procesal para impedir en el caso concreto las actuaciones contra agentes estatales extranjeros. En consecuencia, tal y como señala Hazel Fox, la norma sobre inmunidad funcional no contradice ninguna prohibición contenida en las normas de ius cogens, sino que se limita a remitir sus infracciones a un mecanismo distinto de resolución de controversias ${ }^{103}$.

Esta posición encuentra apoyo en la sentencia de la CIJ en el caso Yerodia, que, como hemos visto, afirma que la prohibición de ciertos crímenes por normas de ius cogens no deroga automáticamente la regulación sobre inmunidad personal. En consecuencia, si la norma sobre inmunidad personal permanece, ¿por qué ha derogarse la norma sobre inmunidad funcional, siendo su naturaleza la misma? ${ }^{104}$.

También se mencionan a este respecto algunas decisiones de la CIJ y la CEDH en material de responsabilidad civil del Estado. En particular se hace referencia al caso sobre las Inmunidades Jurisdiccionales de los Estados, en el que la CIJ ha afirmado que el hecho de que se reconozca la inmunidad de jurisdicción frente a los tribunales nacionales extranjeros, no significa que se esté considerando como lícita la situación generada por la violación de una norma de ius cogens ${ }^{105}$. En este mismo sentido, se ha pronunciado la $\mathrm{CEDH}$ en el caso Al-Adsani c. Reino Unido, al rechazar la posibilidad de que los tribunales nacionales del Reino Unido investigaran la responsabilidad civil del Estado de Kuwait por cometer crímenes de ius cogens como la tortura ${ }^{106}$.

Es en este contexto que Akande y Shah han recurrido a un tercer argumento para afirmar la excepción a la norma de inmunidad funcional en caso de delitos internacionales. Según estos autores, el verdadero conflicto se plantea entre dos normas internacionales de naturaleza procesal (ninguna de las cuales tiene rango de ius cogens): (i) la norma que otorga jurisdicción extraterritorial a los Estados y les impone la obligación de investigar y

\footnotetext{
98 Cervell (2013) p. 188.

99 Cryer et al. (2011) p. 531.

100 Ambos (2013) p. 412.

101 Fox (2004) p. 525.

102 AKande et al. (2011) p. 828.

103 Fox (2004) p. 525.

104 Véase en particular Fox (2004) p. 525, donde comenta el párrafo 24 de la sentencia de la Cámara de los Lores del Reino Unido en el caso Jones v. Ministerio del Interior Al-Mamlaka Al-Arabiya as Sudiya (2004), sentencia de la Corte de Apelación, de 28 de octubre de 2004 (BYIL, LXXV, 2004, pp. 489-504).

105 Alemania v. Italia (2012), CIJ, 3 de febrero de 2012 (caso sobre Inmunidades Jurisdiccionales del Estado, con la intervención de Grecia, párr. 93).

106 Al-Adsani v. Reino Unido (2002), Corte Europea de Derechos Humanos, 21 de noviembre de 2002, Pár. 61-62.
} 
enjuiciar a los agentes estatales extranjeros que hayan cometido este tipo de delitos; y (ii) la norma que atribuye a tales agentes estatales inmunidad funcional frente a los tribunales nacionales extranjeros ${ }^{107}$. Para resolver este conflicto, Akende y Shah, en lugar de acudir a la prevalencia jerárquica entre normas internacionales, acuden al principio lex posterior derogat lex anterior, que, en su opinión, hace que prevalezca la regla que exige el ejercicio de la jurisdicción extraterritorial por ser más nueva ${ }^{108}$.

Sin embargo, autores como Ambos han subrayado que este argumento tiene el problema de basarse en una secuencia temporal de las normas procesales de derecho internacional sobre la que no existe ninguna certeza ${ }^{109}$.

Finalmente, el propio Ambos plantea un cuarto argumento derivado de la ponderación de los intereses en juego ${ }^{110}$. A diferencia de los tres anteriores, este argumento no afirma de manera absoluta la excepción a la norma de inmunidad funcional en caso de delitos internacionales, sino que analiza caso por caso cual es el interés prevalente en juego. En otras palabras, la cuestión es determinar a la luz de los hechos del caso concreto si el interés prevalente de la sociedad internacional es la satisfacción de las víctimas, y la prevención general y especial derivada del castigo de quienes cometen los delitos más graves para la sociedad internacional en su conjunto; o si por el contrario, resulta más importante en el caso concreto garantizar el principio de igualdad soberana de los Estados, la no injerencia de tribunales nacionales extranjeros en el ejercicio de sus competencias soberanas y la conducción pacífica de las relaciones internacionales.

Sin embargo, si bien este modelo de equilibrio de intereses nos permite resolver alguno de los problemas presentados por los otros argumentos, lo cierto es que no está exento de dificultades. Así, es razonable admitir que la posición jerárquica del agente estatal extranjero ha de ser un factor importante a la hora de decantar la balanza a favor de la aplicación de la inmunidad funcional, puesto que a mayor rango jerárquico de aquel, mayor grado de injerencia en los asuntos internos del Estado al que representa y mayor nivel de desestabilización en las relaciones internacionales. En consecuencia, aquellos considerados como máximos responsables, tenderían a disfrutar de un mayor ámbito de inmunidad funcional, a pesar de que el derecho internacional penal centra en los mismos la obligación de los Estados de investigar y enjuiciar los crímenes internacionales de ius cogens.

\section{LA PRÁCTICA INVIABILIDAD DEL ENJUICIAMIENTO POR CRÍMENES INTERNACIONALES ante tribunales nacionales extranjeros de Jefes de Estado, Jefes de Gobierno y Ministros de Asuntos Exteriores \\ La investigación y el enjuiciamiento ante tribunales nacionales extranjeros de Jefes de Estado, Jefes de Gobierno y Ministros de Asuntos Exteriores por crímenes internacio- nales de ius cogens resulta prácticamente inviable. Esta situación resulta incontrovertida cuando se encuentran en el ejercicio de su cargo, al no haberse producido ni la más mínima}

\footnotetext{
107 AKANDE et al. (2011) p. 840.

108 AKANDE et al. (2011) p. 840.

109 Амвоs (2013) p. 413.

110 Аmbos (2013) p. 413.
} 
grieta en la inviolabilidad proporcionada por la inmunidad personal a los mismos. Pero incluso una vez que han abandonado el cargo la situación es ciertamente compleja al no haber podido cristalizar una excepción consuetudinaria al principio de inmunidad funcional.

Ciertamente se puede apreciar una tendencia en la práctica internacional que favorece el progresivo desarrollo de una excepción consuetudinaria a la inmunidad funcional con respecto a crímenes internacionales de ius cogens, Sin embargo, no es menos cierto que el rechazo a esta excepción por un organismo tan autorizado como la CIJ en el caso Yerodia ha supuesto un freno muy importante a la misma, que se ha visto reforzado por la restricciones legislativas introducidas en los últimos años en algunos Estados para limitar el ámbito de actuación de sus tribunales nacionales en base al principio de justicia universal ${ }^{111}$.

Del mismo modo, también existe una clara división de opiniones con respecto a los argumentos que justificarían dicha excepción, lo que en nuestra opinión viene motivado por la artificial ruptura que la CIJ en el caso Yerodia ha introducido en el normal funcionamiento del principio de prevalencia normativa entre normas de distinto rango jerárquico dentro de un mismo ordenamiento jurídico. Lo sorprendente es el amplio número de autores que defienden esta ruptura, a pesar de que la misma entrañe afirmar la existencia de una doble escala normativa dentro del derecho internacional: una para las normas sustantivas y otra para las normas procesales.

En consecuencia, tal como la CIJ ha afirmado en el caso Yerodia, los dos únicos supuestos en los que en la actualidad los Jefes de Estado, los Jefes de Gobierno y los Ministros de Relaciones Exteriores pueden ser investigados y juzgados por delitos internacionales ante tribunales nacionales extranjeros son: (i) cuando el Estado al que representan renuncia a la inmunidad; o (ii) cuando, una vez que se ha producido el cese al cargo, las actuaciones penales se abren en relación con actos privados, lo que como hemos visto en la sección anterior solo es posible a través de una ficción jurídica que no se corresponde con la realidad de los delitos internacionales cometidos por altos representantes del Estado ${ }^{112}$.

Ante la constatada impunidad de que gozan quienes en sus respectivos Estados detentan, o han detentado, el poder, se puede afirmar que a día de hoy la única instancia operativa para el enjuiciamiento por crímenes internacionales de los Jefes de Estado, los Jefes de Gobierno y los Ministros de Asuntos Exteriores son los tribunales internacionales penales.

\section{LA INMUNIDAD FUNCIONAL Y LA INMUNIDAD PERSONAL ANTE TRIBUNALES INTERNACIONALES PENALES}

\section{A. Tribunales internacionales penales distintos de la CPI}

La ausencia de actuaciones penales a nivel nacional frente a quienes desde la más alta representación del Estado promovieron a lo largo del siglo XX la comisión de delitos inter-

111 La última de estas reformas se ha llevado a cabo en España a través de la Ley Orgánica No $1 / 2014$, de 13 de marzo, que modifica la Ley Orgánica $\mathrm{N}^{\circ}$ 6/1985, de 1 de julio, del Poder Judicial, relativa a la justicia universal.

112 República Democrática del Congo v. Bélgica (2002), CIJ, 14 de febrero de 2002 (caso sobre la Orden de Arresto de 11 de abril de 2000, párr. 61). 
nacionales contra decenas de millones de víctimas, llevó a la sociedad internacional a crear tribunales internacionales penales para su investigación y enjuiciamiento.

El primer intento en este sentido se recogió en la recomendaciones de la Comisión de Responsabilidades creada en 1918 por la Conferencia Preliminar de Paz de París ${ }^{113}$, que cristalizaron en el artículo 227 del Tratado de Versales de 1919, donde los aliados acusaron al Kaiser Guillermo II de Alemania de cometer una ofensa suprema contra la moral internacional y la santidad de los Tratados y previeron la creación de un tribunal especial para su juzgamiento $^{114}$. Sin embargo, todo se quedó en un intento frustrado porque el Kaiser Guillermo II, tras abdicar en noviembre de 1918, se refugió en Holanda, que se había mantenido neutral durante la I Guerra Mundial, negándose la reina Guillermina a entregarlo a los aliados ${ }^{115}$.

Hubo por tanto que esperar hasta el Acuerdo de Londres de 8 de agosto de 1945 para que, al término de la II Guerra Mundial, se creara el primer tribunal internacional penal: el Tribunal Militar Internacional con sede en Nuremberg. Para evitar la invocación de inmunidad por parte de los ex altos cargo del gobierno y del ejército alemán, el artículo 7 del Acuerdo de Londres estableció que "[e]l cargo oficial de los acusados, ya sean Jefes de Estado o funcionarios a cargo de Departamentos del Gobierno no les exonerará de las responsabilidades ni servirá para atenuar la pena". Idéntica disposición se incluyó en el artículo 6 del Estatuto del Tribunal Militar Internacional para el Lejano Oriente, con sede en Tokio, que fue creado en 1946 para juzgar a los ex altos miembros del gobierno y del ejército japonés durante la II Guerra Mundial.

El principio de improcedencia del cargo oficial como motivo de exoneración de responsabilidad o atenuación de la pena se incluyó dos años después en la Convención contra el Genocidio ${ }^{116}$, y en 1950 entró a formar parte de los Principios de Nuremberg aprobados por la Asamblea General de las Naciones Unidas ${ }^{117}$. Con ello se consolidó su carácter consuetudinario, que se vio reforzado con su inclusión en la Convención sobre el Apartheid

113 La Comisión de Reparaciones recomendó que "todas las personas de los países enemigos, con independencia de lo elevada que pueda haber sido su posición, sin distinción de rango, incluyendo Jefes de Estado, que han sido culpables de delitos contra las leyes y costumbres de la guerra o las leyes de la humanidad, son susceptibles de persecución penal". Vid. Gaeta, Paola. (2002) p. 1979.

114 Según establece el artículo 227 del Tratado de Versalles: "Las Potencias aliadas y asociadas acusan públicamente a Guillermo II de Hohenzollern, ex emperador de Alemania, por ofensa suprema contra la moral internacional y la santidad de los Tratados. Se constituirá un tribunal especial para juzgar al acusado, asegurándole las garantías esenciales del derecho de defensa.

115 Tampoco fueron juzgados los altos mandos del ejército alemán, en particular Paul von Hinderburg y Erich Ludendorf, quienes desde 1916 tuvieron el control de hecho de Alemania. A este respecto, el artículo 228 del Tratado de Versalles establecía que: "El Gobierno alemán reconoce a las Potencias aliadas y asociadas el derecho de llevar ante sus tribunales militares a los acusados de haber cometido actos contrarios a las leyes y a las costumbres de la guerra”.

116 El artículo III de la Convención contra el Genocidio prevé que "las personas que hayan cometido genocidio o cualquiera de los otros actos enumerados en el artículo III, serán castigados, ya se trate de gobernantes, funcionarios o particulares".

117 El Principio III de los Principios de Nuremberg aprobados por la Asamblea General de las Naciones Unidas en 1950 señala que "el hecho de que la persona que haya cometido un acto que constituya delito de Derecho internacional haya actuado como Jefe de Estado o como autoridad del Estado, no la exime de responsabilidad conforme al Derecho internacional”. 
de $1979^{118}$, los Proyectos de Código de Crímenes Internacionales contra la Paz y Seguridad Internacional elaborados por la CDI en $1991^{119}$ y $1996^{120}$ y los artículos 7(2) del ETIPY $(1993)^{121}, 6(2)$ del ETIPR $(1994)^{122}$, 6(2) del ECESL (2002) ${ }^{123}$ y 29 de ESECC (2004) ${ }^{124}$.

Es de observar que todas estas disposiciones parecen tener una naturaleza sustantiva en cuanto que rechazan la configuración del cargo oficial como una causal de exoneración de responsabilidad o de atenuación de la pena. Sin embargo, como ya hemos visto, tanto la inmunidad personal como la inmunidad funcional son obstáculos de naturaleza procesal para el ejercicio de la jurisdicción penal. En consecuencia, surge la pregunta de si tales disposiciones establecen una auténtica excepción consuetudinaria al principio de inmunidad, o si por el contrario no hacen sino recoger una norma autónoma de carácter sustantivo. Además, en el primer caso, surge una segunda cuestión relativa a si dicha excepción afecta tanto a la inmunidad personal como a la funcional, o solamente a esta última.

Con respecto a la primera cuestión, a pesar de que la redacción utilizada para definir el principio de improcedencia del cargo oficial parece referirse a una causal de exoneración de responsabilidad o atenuación de la pena, lo cierto es que, como Ambos ha subrayado, existe una alto grado de consenso entre la doctrina y la jurisprudencia de los distintos tribunales internacionales sobre su naturaleza de excepción consuetudinaria a la regla de inmunidad funcional ${ }^{125}$. Esta excepción se fundamenta en que las actuaciones penales desarrolladas por los tribunales internacionales en nombre de la comunidad internacional en su conjunto no afectan al principio de igualdad soberana entre los Estados, que es el fundamento de la inmunidad funcional ${ }^{126}$. Ejemplos de la aplicación de esta excepción es el enjuiciamiento ante el TIPR de Jean Kambanda, quien fuera primer ministro durante

\footnotetext{
118 El artículo III de la Convención sobre el Apartheid de 1979, establece que: "Se considerarán criminalmente responsables en el plano internacional cualquier que sea el móvil, los particulares, los miembros de organizaciones e instituciones y los representantes del Estado, tanto si residen en el territorio del Estado en que se perpetran los actos como en cualquier otro Estado".

119 De acuerdo con el artículo 13 del Proyecto de Código de Crímenes Internacionales contra la Paz y Seguridad Internacional de 1991: "El carácter oficial del autor de un crimen contra la paz y la seguridad de la humanidad, y en especial el hecho de que haya actuado como jefe de Estado o de gobierno, no lo eximirá de responsabilidad criminal", Anuario de la CDI, 1991, vol. II. A/CN.4/SER.A/1991.

120 Conforme al artículo 7 del Proyecto de Código de Crímenes Internacionales contra la Paz y Seguridad Internacional de 1996: "El carácter oficial del autor de un crimen contra la paz y seguridad de la humanidad, incluso si actuó como Jefe de Estado o de Gobierno, no lo eximirá de responsabilidad criminal ni atenuará su castigo". Vid. informe de la CDI a la Asamblea General de las Naciones Unidas sobre los trabajos realizados en su $48^{\circ}$ periodo de sesiones, Anuario de la CDI, 1996, vol. II, segunda parte, p. 29.

121 El artículo 7 (2) del ETIPY (Estatuto del Tribunal Penal Internacional para la Antigua Yugoslavia) dispone que "[e]l cargo oficial que desempeñe el inculpado, ya sea de Jefe de Estado o de Gobierno o de funcionario responsable del gobierno, no le eximirá de responsabilidad penal ni atenuará la pena”.

122 El artículo 6 (2) del ETIPR (Estatuto del Tribunal Penal International para Ruanda) tiene el mismo contenido que el artículo 7(2) del EIPY.

123 El artículo 6(2) del ECESL (Estatuto Corte Especial para Sierra Leona) tiene el mismo contenido que el artículo 7(2) del ETIPY y el artículo 6(2) del ETIPR.

124 El artículo 29 del ESECC (Estatuto Salas Especiales de las Cortes de Cambodia) tiene el mismo contenido que el artículo 7(2) del ETIPY, el artículo 6(2) del ETIPR y el artículo 6(2) del ECESL.

125 Ambos (2013) p. 415.

126 VV. AA. CRYer (2011) p. 551; AKANde (2004) p. 417.
} 
el genocidio en Ruanda entre abril y junio de $1994^{127}$, así como el proceso seguido ante las SECC contra Khieu Samphan, antiguo Jefe de Estado de la República de Kampuchea durante el régimen de los yémeres rojos a finales de los años $1970^{128}$.

Con respecto a la segunda cuestión, las divisiones son más ostensibles. Por un lado, Cryer ${ }^{129}$ y Akande ${ }^{130}$ consideran que el hecho de que las actuaciones penales se desarrollen ante tribunales internacionales no genera ninguna excepción consuetudinaria a la inmunidad personal.

Para Cryer los tribunales internacionales son creados por Estados y, por lo tanto, no les es posible establecer una institución que tenga la facultad de realizar aquello que no les está permitido a los propios Estados en aplicación de la norma consuetudinaria de inmunidad personal ${ }^{131}$.

Por su parte, Akande afirma que solo sería posible aceptar la inaplicación de la inmunidad personal ante los tribunales internacionales penales cuando en el acto de creación de estos últimos se contenga una renuncia implícita o explícita del Estado cuyos representantes van a ser investigados y enjuiciados. Así por ejemplo, en el caso de la CESL y de las SECC, la inaplicación de la inmunidad personal para los agentes estatales de Sierra Leona y Camboya se fundamenta en la renuncia a la misma por parte de ambos Estados en los acuerdos que suscribieron con el Secretario General de las Naciones Unidas para la creación de dichos tribunales ${ }^{132}$.

En cuanto al TIPY y al TPIR -creados por resoluciones del Consejo de Seguridad actuando conforme al capítulo VII de la Carta de las Naciones Unidas, que en virtud de los artículos 25 y 103 de la misma son de obligatorio cumplimiento para todos sus miembros, para Akande lo que ocurre es que cada uno de los Estados miembros de la ONU (cuyo ámbito es universal), al entrar a formar parte de la misma, acepta voluntariamente la obligación de cumplir de manera preferente con las resoluciones dictadas por el Consejo de Seguridad en desarrollo de las competencias que se le han conferido para el mantenimiento de la paz y seguridad internacional. Esta es también la posición defendida por Schabas al subrayar que no es posible alegar la inmunidad personal frente a órganos jurisdiccionales creados por el Consejo de Seguridad con base en el capítulo VII, pues existe la obligación de cooperar con los mismos ${ }^{133}$.

Una segunda posición es defendida por Cassese y Gaeta, quienes afirman la existencia de una excepción consuetudinaria que haría inaplicables tanto la inmunidad funcional como la inmunidad personal frente a los tribunales internacionales penales ${ }^{134}$. Esto sería así incluso en el caso del Tribunal Especial para el Líbano, en cuyo Estatuto no se recoge ninguna mención a la improcedencia del cargo oficial ${ }^{135}$. Para estos autores, el objeto de ambos tipos de inmunidad es evitar el peligro de cualquier interferencia de terceros Estados

127 Prosecutor v. Kambanda (1998); TPIR, Sala de Juicio, 4 septiembre 1998. Pár. 39.

128 Prosecutor v. Samphan (2014); ESECC, Sala de Juicio, 7 agosto, 2014.

129 CRYER et al. (2011) p. 551.

130 AKANDE et al. (2004) p. 417.

131 CrYer et al. (2011) p. 551.

132 Akande (2004) p. 417.

133 Shabas (2010) p. 450.

134 Gaeta (2009) pp. 320 y ss.

135 Cassese (2008) p. 311. 
en el desarrollo de las funciones de los agentes estatales ${ }^{136}$. En consecuencia, dado que los tribunales internacionales actúan siempre en nombre de la comunidad internacional en su conjunto, y sus jueces son independientes, imparciales y expertos en la materia, no es posible que pueda materializarse dicho peligro ${ }^{137}$.

Cassese y Gaeta encuentran apoyo para su posición en la temprana jurisprudencia del TIPY, que, como veíamos en secciones anteriores, ha afirmado en los casos Blaskic, Furundzija, Karadzic y Milosevic la inaplicación de todo tipo de inmunidad en relación con los crímenes internacionales, con independencia de que las actuaciones se desarrollen ante tribunales internacionales penales, o ante tribunales nacionales extranjeros ${ }^{138}$. Particularmente relevante es el caso contra Slobodan Milosevic porque en el momento de iniciarse las actuaciones penales contra el mismo en 1999 mantenía la posición de Jefe de Estado de la República Federal de Yugoslavia ${ }^{139}$.

Cassese y Gaeta encuentran también apoyo en la jurisprudencia de la CESL, que inició sus actuaciones contra Charles Taylor en 2003, cuando todavía era Jefe de Estado de Liberia. Al año siguiente, la Sala de Apelaciones de la CESL afirmó que al ser un tribunal internacional creado con base en un acuerdo entre las Naciones Unidas y el gobierno de Sierra Leona, no era viable alegar ningún tipo de inmunidad, ya que estas solo pueden invocarse en procesos que se lleven a cabo ante tribunales de Estados soberanos ${ }^{140}$.

La Sala de Apelaciones de la CESL cita a su vez la sentencia de la CIJ en el caso Yerodia, donde de manera general se deja abierta la posibilidad de inaplicar cualquier tipo de inmunidad de los Jefes de Estado, los Jefes de Gobierno y los Ministros de Relaciones Exteriores (ya se encuentren en ejercicio, o hayan cesado en el cargo) cuando sean investigados y enjuiciados por tribunales internacionales penales que tengan jurisdicción ${ }^{141}$.

\section{B. Corte Penal Internacional}

Para evitar que la división sobre el alcance del principio de improcedencia del cargo oficial pudiera afectar al efectivo ejercicio de la jurisdicción de la Corte Penal Internacional, el artículo 27 del Estatuto de la CPI, aprobado en junio de 1998 y en vigor desde julio de 2002, dedica dos apartados a la cuestión. En el primero se recoge la tradicional definición

\footnotetext{
136 CASSESE (2008) p. 331.

137 CASSESE (2008) p. 312 y GaEta (2009) p. 321.

138 Fiscal v. Blaškić (1997); TPIY, sala de apelaciones, Fallo sobre la Solicitud de Croacia para la revisión de la decisión de la Sala de Juicio II del 18 de julio de 1997, fallo del 29 de octubre de 1997, párrafo 41. En el mismo sentido, Fiscal v. Karadzić (1995); TPIY, sala de juicio sobre la solicitud de Bosnia, 16 de mayo de 1995, párr. 24; Fiscal v. Furundzija (1998); TPIY Sala de Juicio, sentencia del 10 de diciembre de 1998, Párr. 140 y ss.; y, Fiscal v. Milosevic Slobodan (2001); TPIY, decisión sobre excepciones preliminares, 8 de noviembre de 2001, Pár. 28.

139 Fiscal v. Milosevic Slobodan (2001); TPIY, decisión sobre excepciones preliminares, 8 de noviembre de 2001.

140 Fiscal v. Charles Taylor (2004), CESL, Sala de Apelaciones, Decisión acerca de la inmunidad de jurisdicción, 31 de mayo de 2004. Par. 50-54. De esta forma, el TESL sostuvo que contaba con competencia para confirmar la acusación de la fiscalía (7 marzo de 2003) contra Charles Taylor, que en ese momento ostentaba el cargo de Jefe de Estado de Liberia y solicitar a INTERPOL una orden de arresto internacional en su contra.

141 República Democrática del Congo v. Bélgica (2002), CIJ, 14 de febrero de 2002 (caso sobre la Orden de Arresto de 11 de abril de 2000, párr. 61).
} 
del principio de improcedencia del cargo oficial ${ }^{142}$, mientras que en el segundo se establece que "[l]as inmunidades y las normas de procedimiento especiales que conlleve el cargo oficial de una persona, con arreglo al Derecho interno o al Derecho internacional, no obstarán para que la Corte ejerza su competencia sobre ellas"143.

A través de este segundo apartado los redactores del Estatuto de la CPI se aseguraron expresamente que la inmunidad personal de los Jefes de Estado, los Jefes de Gobierno y los Ministros de Relaciones Exteriores no sería aplicable ante la CPI ${ }^{144}$. En consecuencia, existe en la doctrina un alto grado de consenso en que cada uno de los Estados partes del Estatuto de la CPI (en la actualidad son ciento veintidós), ha renunciado de manera expresa a toda inmunidad personal y funcional que sus agentes pudieran haber tenido frente a la CPI conforme al derecho internacional consuetudinario ${ }^{145}$. Además, la propia jurisprudencia de la CPI en el caso contra el actual Jefe de Estado de Sudán, Omar al Bashir, se ha pronunciado en este mismo sentido ${ }^{146}$.

Esta situación tiene importantes implicaciones en relación con el régimen de cooperación con la CPI, y en particular con el artículo 98 (1) del Estatuto de la Corte Penal Internacional ("ECPI"), que establece que "la Corte no dará curso a una solicitud de entrega o de asistencia en virtud de la cual el Estado requerido deba actuar en forma incompatible con las obligaciones que le imponga el derecho internacional con respecto a la inmunidad de un Estado o la inmunidad diplomática de una persona o un bien de un tercer Estado, salvo que la Corte obtenga anteriormente la cooperación de ese tercer Estado para la renuncia a la inmunidad".

De esta manera, cuando en el marco de un caso contra un Jefe de Estado, un Jefe de Gobierno o un Ministro de Relaciones Exteriores de un Estado Parte (con independencia de que se encuentre en ejercicio o haya abandonado el cargo), la CPI realice una solicitud de entrega o de asistencia judicial a un Estado que tenga la obligación de cooperar con la misma en el caso concreto -ya se deba a que es un Estado Parte, a que a pesar de no ser un Estado parte así se ha obligado conforme al art. 87(5) del ECPI, o a que el Consejo de Seguridad así lo ha establecido por resolución del capítulo VII de la Carta de las Naciones Unidas $^{147}$-, el Estado requerido no podrá rechazar el cumplimiento de dicha solicitud de cooperación excusándose en que ello le obligaría a violar una presunta obligación consuetudinaria de respetar la inmunidad personal del imputado ${ }^{148}$. Esta es precisamente la situa-

\footnotetext{
142 Conforme al artículo 27 (1) del ECPI, "El presente Estatuto será aplicable por igual a todos sin distinción alguna basada en el cargo oficial. En particular, el cargo oficial de una persona sea Jefe de Estado o de Gobierno, miembro de un Gobierno o Parlamento, representante elegido o funcionario de Gobierno, en ningún caso la eximirá de responsabilidad penal ni constituirá per se motivo para reducir la pena”.

143 Artículo 27 (2) ECPI.

144 Ambos (2013) p. 415.

145 VV.AA. Shabas (2010) p. 450; Werle (2009) p. 654; Cryer et al. (2011), pp. 554-555; Ambos (2013) p. 415.

146 Prosecutor v. Omar Hassan Ahmad Al Bashir, CPI, Núm. ICC-02/05-01/09-139-Corr, párr. 18.

${ }_{147}$ Ver resolución 1593 de 31 de marzo de 2005, del Consejo de Seguridad de las Naciones Unidas, que además de remitir la situación en Darfur (Sudán) a la Fiscalía de la Corte Penal Internacional, imponía al Estado de Sudán, a pesar de ser un Estado no parte del Estatuto de la CPI, la obligación de cooperar con la CPI en todas las actuaciones relativas a la situación en Darfur.

148 VV.AA. Akande (2004) p. 420; Gaeta (2009) p. 328; Cassese et al. (2002) p. 994.
} 
ción que se ha planteado en relación con el enjuiciamiento ante la CPI del Jefe de Estado en ejercicio de la República de Kenia, Urumu Kenyatta ${ }^{149}$.

El problema se presenta cuando la CPI pretende desarrollar actuaciones contra Jefes de Estado, Jefes de Gobierno o Ministros de Relaciones Exteriores en ejercicio de Estados no parte del Estatuto de la CPI. En estos casos, el Estado al que el imputado representa no ha renunciado expresamente a la inmunidad personal que el mismo pudiera tener, conforme al derecho internacional consuetudinario, ante un tribunal internacional como la CPI. En consecuencia, se hace necesario conocer si el alcance de la excepción consuetudinaria a dicha inmunidad: (i) se limita a la inmunidad funcional como $\operatorname{Cryer}^{150}$, Akande $^{151} \mathrm{o}$ Schabas ${ }^{152}$ afirman, en cuyo caso el Estado requerido podría rechazar invocando el artículo 98 (1) del ECPI toda solicitud de la CPI para la entrega del imputado o la asistencia judicial $^{153}$; o (ii) se extiende también a la inmunidad personal como Cassese ${ }^{154}$ y Gaeta ${ }^{155}$ sostienen, lo que impediría al Estado requerido invocar el artículo 98 (1) del ECPI.

La CPI ha abordado esta cuestión en el caso contra Omar Al Bashir ${ }^{156}$, donde acogió expresamente la posición que afirma que el derecho internacional consuetudinario establece una excepción a la inmunidad personal de los Jefes de Estado en ejercicio, de manera que esta no puede ser invocada ante tribunales internacionales como la CPI ${ }^{157}$. Con ello, se ha seguido la línea marcada por la jurisprudencia del TIPY ${ }^{158}$ y de la CESL ${ }^{159}$.

149 Prosecutor c. Francis Kirimi Muthaura and Uhuru Muigai Kenyatta; CPI, Núm. ICC-01/09-02/11-38. La República de Kenia ha sido Estado parte del ECPI desde marzo de 2005.

150 CRYer (2011) p. 551.

151 AKANDE (2004) p. 417.

152 SHABAS (2010) p. 450.

153 La disposición "tercer estado" aplica respecto de los Estados no parte del estatuto como bien lo han sostenido VV.AA. Akande (2004) p. 420; Papillon, (2010) p. 283; Kreb (2012) p. 238.

154 CASSESe (2008) p. 311.

155 GaETA (2009) pp. 320 y ss.

156 Inicialmente, en su decisión de 4 de marzo de 2009, la CPI ofreció las siguientes cuatro razones para afirmar que la posición de Jefe de Estado en ejercicio de un Estado no parte no suponía ningún impedimento para el ejercicio de la jurisdicción de la CPI porque: (i) el objetivo de la CPI según el Preámbulo de su estatuto es poner fin a la impunidad y castigar a los autores de los crímenes más graves para la comunidad internacional en su conjunto; (ii) el artículo 27 del ECPI afirma expresamente que ningún tipo de inmunidad es aplicable ante la CPI; (iii) el artículo 21 del ECPI establece el sistema de fuentes de la CPI por el que se ha de aplicar en primer lugar lo dispuesto en el ECPI, los Elementos de los Crímenes y las Reglas de Procedimiento y Prueba, siendo solo posible acudir a otras fuentes (incluido el propio derecho internacional consuetudinario), (iv) el hecho de que Sudán no sea un Estado parte del ECPI no cambia en nada la cuestión relativa a la inmunidad, puesto que el Consejo de Seguridad, al referir la situación en Darfur a la Fiscalía de la CPI, aceptó que sería el ECPI en su conjunto el que regiría las investigaciones y enjuiciamientos que se llevarían a cabo ante la CPI con respecto a la situación en Sudán.

157 Esta cuestión no fue, sin embargo, abordada en el caso contra Muammar Gaddafi, quien ostentaba el cargo de Jefe de Estado de Libia cuando el 16 de mayo de 2011 la Fiscalía de la CPI solicitó la emisión de una orden de arresto contra el mismo, su hijo Said Al-Islam Gaddafi y Mohamed Al-Senussi. Decisión sobre la solicitud de Libia en relación con el arresto de Saif Al-Islam Gaddafi, ICC-01/11-01/11-72, de 7 de marzo de 2012.

158 Prosecutor v. Blaškić (1997); TPIY, Appeals Chamber, Judgement on the Request of the Republic of Croatia for Review of the Decision of Trial Chamber II of 18 July 1997, Judgement of 29 October 1997, párrafo 41. En el mismo sentido, Fiscal v. Karadzić (1995); TPIY, Decisión de la Sala de Juicio sobre la solicitud de Bosnia, 16 de mayo de 1995 párr. 24; Fiscal v. Furundzija (1998), TPIY, Sala de Juicio, sentencia del 10 de diciembre de 1998, Párr. 140 y ss.; y Fiscal c. Milosevic Slobodan (2001), TPIY, decisión sobre excepciones preliminares, 8 de noviembre de 2001, Pár. 28.

159 Prosecutor v. Charles Taylor (2004), TPIY, Sala de Apelaciones, Decisión acerca de la inmunidad de jurisdicción, 31 de mayo de 2004. Par. 50-54. 
Si bien estas decisiones han sido criticadas por una parte de la doctrina y en particular por la Unión Africana ${ }^{160}$, lo cierto es que las mismas refuerzan la afirmación de Cassese y Gaeta relativa a la existencia en el derecho internacional consuetudinario de una excepción a la aplicación de la norma de inmunidad personal cuando se trata de actuaciones ante tribunales internacionales penales ${ }^{161}$.

Además, varios autores que no coinciden con esta posición han aceptado sin embargo la inaplicación por la CPI de la inmunidad personal de Omar Al Bashir y de Muammar Gaddafi con base en otros argumentos. Así, Akande ha afirmado que Sudán y Libia entran a ser considerados como análogos a Estado parte del ECPI, a los que se les aplica el artículo 27 ECPI, debido a que ambas situaciones han sido remitidas por resoluciones del Consejo de Seguridad en ejercicio de las competencias que le atribuye el capítulo VII de la Carta de las Naciones Unidas ${ }^{162}$.

En el mismo sentido, Papillon ha señalado que todos los Estados parte de las Naciones Unidas accedieron en el momento de ratificar su Carta a que el Consejo de Seguridad pudiera adoptar medidas para garantizar la paz y seguridad internacionales, incluyendo la posibilidad de que se revocara en algún momento la inmunidad de los altos representantes de sus Estados, lo que se ha producido implícitamente con la remisión a la Fiscalía de la CPI de las situaciones en Darfur y Libia ${ }^{163}$.

Finalmente, para Ambos es más convincente acudir a un ejercicio de ponderación de los intereses en juego: el interés de la comunidad internacional en evitar la impunidad de los crímenes internacionales, y el interés de los Estados no parte del ECPI en no verse afectados por la regla de no inmunidad del artículo 27 del ECPI. Para esta autor, al tratarse la CPI de un tribunal internacional con un alcance casi universal, y tener el apoyo del Consejo de Seguridad a través de sus remisiones, ha de darse preferencia al primero de dichos intereses $^{164}$.

\section{CONCLUSIÓN}

Tras siete décadas de proceso de humanización del derecho internacional, el tradicional escudo de protección con que el Estado como institución ha contado para no responder ante tribunales nacionales extranjeros por los daños causados por sus actos de iure imperii permanece inalterado.

\footnotetext{
160 La Unión Africana ha lamentado profundamente estas decisiones puesto que, en su opinión, las mismas tenían como efecto: (i) tratar de modificar el derecho internacional consuetudinario relative a la inmunidad personal; (ii) convertir al artículo 98 del ECPI en redundante, inoperativo y privado de todo contenido; (iii) tomar decisiones per in curiam, al referirse a decisiones de la Unión Africana ignorando completamente el artículo 23 (2) del Acta Constitutiva de la Unión Africana, de la que tanto Chad como Malawi son Estados Partes; y (iv) obligar a todos los miembros de la Unión Africana a cumplir con las decisiones y políticas de la Unión.

161 VV.AA. CASSESe (2008) p. 311; GAETA (2009) pp. 320 y ss.

162 Akande (2009) p. 342.

163 Papillon (2010) p. 285.

164 Ambos (2013) p. 285.
} 
Del mismo modo, no se ha producido ni la más mínima grieta en la inviolabilidad proporcionada frente a los tribunales nacionales extranjeros por la inmunidad personal de sus altos representantes en ejercicio: Jefes de Estado, Jefes de Gobierno y Ministros de Asuntos Exteriores. Ello es así incluso en el caso de crímenes internacionales de ius cogens.

La situación no difiere mucho cuando los agentes estatales han abandonado el cargo. El progresivo desarrollo de una excepción consuetudinaria a su inmunidad funcional cuando los tribunales nacionales extranjeros les imputan crímenes internacionales, se ha visto frenado por el rechazo de la CIJ a esta excepción en el caso Yerodia, el cual ha venido a costa de romper con el normal funcionamiento del principio de prevalencia normativa entre normas de distinto rango jerárquico dentro del ordenamiento jurídico internacional. Las restricciones legislativas introducidas en los últimos años en algunos Estados para limitar el ámbito de actuación del principio de justicia universal a nivel nacional no ha hecho sino reforzar este frenazo.

En consecuencia, en la actualidad es prácticamente inviable la investigación y el enjuiciamiento por crímenes internacionales de Jefes de Estado, Jefes de Gobierno y Ministros de Asuntos Exteriores ante tribunales nacionales extranjeros. Por ello, ante la constatada impunidad de la que disfrutan en sus Estados de origen, los tribunales internacionales penales aparecen como la única instancia operativa para su procesamiento.

Sin embargo, estos últimos son absolutamente insuficientes dada su limitada capacidad material de actuación frente a los cientos de miles, sino millones, de delitos internacionales que durante cada década del siglo XX, y en lo que llevamos de siglo XXI, se han generado desde el poder estatal.

Además, a pesar de la jurisprudencia constante de la CPI, el TIPY y la CESL desde 1998, un buen número de autores y actores políticos se aferra a mantener cuando menos la inmunidad personal de los Jefes de Estado, los Jefes de Gobierno y los Ministros de Asuntos Exteriores en ejercicio.

Las justificaciones para la preservar la inmunidad del Estado en cuanto institución y de sus más altos representantes políticos son numerosas. Para algunos es necesario tratar de proteger en la mayor medida posible el principio de soberanía de los Estados. Para otros, de lo que se trata es de proteger las relaciones internacionales sin que haya ningún tipo de interferencia en el desarrollo de las funciones soberanas de un Estado por sus más altos representantes $^{165}$.

El problema es que esta situación se dirige directamente contra la línea de flotación del proceso de humanización del derecho internacional. ¿Es posible que podamos afirmar la importancia del respeto de la dignidad humana como criterio ético-material de actuación de la actual sociedad internacional, cuando la preservación de las relaciones entre los Estados justifica el sacrificio de la dignidad de tantas personas humanas como sea necesario?

Finalmente, cabe preguntarse, ¿̇hasta qué punto no se ha producido sino un mero "barniz" de humanización, de manera que los criterios ético-materiales que estuvieron a punto de llevarnos a la destrucción del planeta en el siglo XX, siguen rigiendo el actuar de

165 En este sentido, no son pocos los que afirman que las excepciones al principio de inmunidad fomentaría la apertura de actuaciones por motivos políticos sin la existencia de pruebas firmes de la comisión de delitos internacionales. Vid. a este respecto, el recuento de los diversos argumentos presentados en Cervell (2013) pp. 190-191. 
los miembros de la actual sociedad internacional? Y si este es el caso, ¿̇será que en el fondo no hemos aprendido nada del pasado, y nos hemos autoconvencido de que actuando de la misma manera llegaremos a resultados diferentes?

\section{BIBLIOGRAFÍA CITADA}

Abello, Ricardo (2011): "Introducción al estudio de las normas de Ius Cogens en el seno de la Comisión de Derecho Internacional”, Vniversitas, Núm. 123, julio-diciembre 2011: pp. 89-92.

Akande, Dapo (2004): "International Law Immunities and the International Criminal Court", AJIL, Vol. 98: pp. 407-433.

AKande, Dapo y Shah, Sangeeta (2011): "Immunities of State Officials, International Crimes, and Foreign Domestic Courts”, EJIL, Vol. 22, No 4: pp. 817-852.

Aмвos, Kai (2013): Treatise on International Criminal Law, Volume I: Foundation and General Part (Reino Unido, Editorial Oxford University Press).

Bassiouni, Mahmoud Cherif (1980): International Criminal Law: A Draft International Criminal Code (Holanda, Editorial Sijhoff \& Noordhoff, Alphen aan den Rijn).

Bassiouni, Mahmoud Cherif (2003): Introduction to international criminal law (Editorial Ardsley Transnational Publishers).

Bassiouni, Mahmoud Cherif (2011): Crimes against Humanity - Historical Evolution and Contemporary Application (Cambridge, Editorial Cambridge University Press).

BianchI, Andrea (1999): "Immunity Versus Human Rights: The Pinochet Case" 10 EJIL: pp. 237-277.

Brotons, Remiro, Riquelme Cortado, R., Orihuela Calatayud, E, Diez-HorchleitCher, J. \& Pèrez-Prat Durán, L. (2010): Derecho Internacional Curso General (Editorial Tirant lo Blanch).

Cahier, P (1965): Derecho Diplomático Contemporáneo (Madrid, Editorial Rialp)

Cassese, Antonio (2002): "When May Senior State Official be Tried for International Crimes? Some Comments on the Congo v. Belgium Case", 13 EJIL: pp. 853-875.

CASSESE, Antonio (2008): International Criminal Law (Oxford, Editorial Oxford University Press, segunda edición).

Cervell Hortal, María José (2013): Genocidio, Responsabilidad Internacional e Inmunidad de los Jefes de Estado (Madrid, Editorial Iustel).

Cryer, Robert, Friman, Hakan, Robinson, Darryl \& Wilmshurst, Elizabeth (2011): An Introduction to International Criminal Law (Editorial Cambridge University Press, segunda edición).

DamgaARD, Ciara (2008): Individual Criminal Responsibility for Core International Crimes (Editorial Springer).

Esposito Massini, Carlos (2007): Inmunidad del Estado y derechos humanos (Madrid, Editorial Thomson Civitas).

Focarelli, Carlos (2008): “Immunité des Etats et ius cogens. La dynamique du Droit International et la fonction de ius cogens dans le proces sus de changement de la règle 
sur l'immunité jurisdictionelle des Etas étrangers", Revue generale de droit international public (RGDIP), vol. 112, No 4: pp. 761-795.

Fox, Hazel (2004): The Law of State Immunity (Reino Unido, Oxford University Press, tercera edición).

Gaeta, Paola (2009): “Does President Al Bashir Enjoy Immunity from Arrest?” 7 JICJ: pp. 315-332.

Hannikainen, Lauri (1988): Peremptory norms (Ius cogens) in International Law: Historical development, criteria, present status (Editorial Finnish Lawyers' Publishing Company).

Kharkhordin, Oleg (2001): "What Is the State? The Russian Concept of Gosudarstvo in the European Context". History and Theory, Vol. 40, No. 2: pp. 206-240.

LAsKI, Harold (2008): The State in Theory and Practice (Transaction Publishers New Brunswick, New Jersey).

Olasolo, Hector (2003): Corte Penal Internacional: ¿Dónde Investigar? (Editorial Tirant lo Blanch, sección II.2.1).

Olasolo, Héctor (2014a): "Dignidad Humana, Derecho Internacional Penal y Justicia de Transición", Revista de Estudios Socio Jurídicos, Vol. 16: pp. 7-20.

Olasolo, Héctor (2014b): "Los exámenes preliminares de la Corte Penal Internacional en América Latina: el caso colombiano y su impacto sobre futuras negociaciones de paz en la región”, en Anuario de Derechos Humanos, Vol. 10: pp. 45-49.

Olasolo, Héctor (2014c): Introducción al Derecho Internacional Penal (Editorial Tirant lo Blanch, Universidad del Rosario \& Instituto Ibero-Americano de la Haya).

Papillon, Sophie (2010): "Has the United Nations Security Council Implicitly removed Al Bashir's Immunity?”, International Criminal Law Review 10: pp. 275-288.

SATZGer, Helmut (2012): International and European Criminal Law (München, Editorial Hart/Beck).

Schwelb, Egon (1967): "Some aspects of International Ius Cogens as formulated by the International Law Commission”, en: American Journal of International Law, vol. 61: pp. 946-975.

Shabas, William (2010): The International Criminal Court: A Commentary on the Rome Statute (Editorial Oxford University Press).

RagazzI, Maurizio (1997): The concept of International Obligations Erga omnes (Editorial Oxford: Clarendon Press).

Van Alebeek, Rosanne (2008): The Immunities of States and their Officials in International Criminal Law and International Human Rights Law (Editorial Oxford University Press).

Weber, Max (1968): Gesammelte Aufsdtze zur Wissenschaftslehre (Tibingen: Mohr).

Werle, Gerhard (2009): Principles of International Criminal Law (The Hague, M. M.C. Asser Press, 2a Edición).

Werle, Gerhard (2011): Tratado de Derecho Penal Internacional (Valencia: Tirant lo Blanch). Zappala, Salvatore (2001): "Do Heads of State in Office Enjoy Immunity from Jurisdiction for International Crimes? the Ghaddafi Case Before the French Cour de Cassation”, EJIL, vol. 12 N. 3. 


\section{JURISPRUDENCIA CITADA}

Sentencia del Tribunal Militar Internacional de Núremberg, de 1 de octubre de 1946.

Sentencia del Tribunal Militar Internacional para el Lejano Oriente, de 4 de noviembre de 1948.

Sentencia del Tribunal Supremo Griego, de 4 de mayo de 2000.

Sentencia del Tribunal Supremo Italiano, de 11 de mayo de 2001.

Auto de la Sala Penal de la Audiencia Nacional de España, de 23 de diciembre de 1998.

Auto de la Sala Penal de la Audiencia Nacional de España, de 4 de marzo de 1999.

Auto de la Sala Penal de la Audiencia Nacional de España, de 13 de diciembre de 2007.

Auto del Juzgado núm. 4 de la Audiencia Nacional de España, de 6 de febrero de 2008.

Al-Adsani v. Reino Unido (2002): Corte Europea de Derechos Humanos, 21 de noviembre de 2002, párr. 61-62.

Alemania v. Italia (2012): CIJ, 3 de febrero de 2012 (caso sobre Inmunidades Jurisdiccionales del Estado, párr. 129).

Barrios Altos vs. Perú (2001): Corte IDH, 14 de marzo de 2001.

Bouzari v. Irán (2002), Tribunal Supremo de Justicia de Ontario, 1 de mayo de 2002.

Djibuti v. Francia (2008): CIJ, 4 de junio de 2008 (Caso sobre Ciertas Cuestiones de Asistencia Mutua en Materia Penal, párr. 194).

España v. Belgica (1970): CIJ, 5 de febrero de 1970 (Barcelona Traction, Light and Power Compagny Limited, párr. 33).

Ferdinand et Imelda Marcos v. Office fédéral de la pólice (1989): Tribunal Federal (Suiza), sentencia de 2 de noviembre de 1989.

Fiscal v. Blaškić (1997): TPIY, fallo del 29 de octubre de 1997.

Fiscal v. Karadzić (1995): TPIY, sala de juicio sobre la solicitud de Bosnia, 16 de mayo de 1995.

Fiscal v. Furundzija (1998): TPIY Sala de Juicio, sentencia del 10 de diciembre de 1998.

Fiscal v. Milosevic Slobodan (2001): TPIY, decisión sobre excepciones preliminares, 8 de noviembre de 2001, Pár. 28.

Fiscal v. Charles Taylor (2004): CESL, Sala de Apelaciones, Decisión acerca de la inmunidad de jurisdicción, 31 de mayo de 2004. Par. 50-54.

Fotso v. Republic of Cameroon (2013): Tribunal de Distrito de Oregon (Estados Unidos), sentencia de 22 de febrero de 2013.

Giménez Espósito v. RFA (2004): Cour de Cassation, 1a Cámara Civil, sentencia de 2 de junio de 2004.

Godinez Cruz vs. Honduras (1989): Corte IDH, 20 de enero de 1989.

Jones v. Ministerio del Interior Al-Mamlaka Al-Arabiya as Sudiya (2004): Corte de Apelación, 28 de octubre de 2004.

Kadhafi (2001): Tribunal de Casación, Sala de lo Penal (Francia), sentencia No 1414, de 13 de marzo de 2001.

Kalogeropoulos v. Grecia y Alemania (2002): Corte Europea de Derechos Humanos, 12 de diciembre de 2002. 
Kline v. Kaneko (1988): Corte Suprema del Estado de Nueva York, sentencia de 31 de octubre de 1988.

Lafontant v. Aristide (1994): Tribunal de Distrito, Distrito Este de Nueva York (Estados Unidos), sentencia de 27 de enero de 1994.

Natoniewski (2010): Corte Suprema de Polonia, en Polish Yearbook of International Law, vol. XXX, 2010, p. 299.

Mobutu v. SA Cotoni (1988): Tribunal civil de Bruselas, sentencia de 29 de diciembre de 1988.

Nicaragua v. Estados Unidos (1986): CIJ, 27 de junio de 1986 (Actividades militares y paramilitares en y contra Nicaragua, párr. 190).

Portugal v. Australia (1996): CIJ, 30 de junio de 1995 (Caso relativo a Timor Oriental, párr. 29).

Prosecutor v. Kambanda (1998): TPIR, Sala de Juicio, 4 septiembre 1998. Pár. 39.

Prosecutor v. Charles Taylor (2004): TPIY, Sala de Apelaciones, Decisión acerca de la inmunidad de jurisdicción, 31 de mayo de 2004.

Prosecutor v. Samphan (2014): ESECC, Sala de Juicio, 7 agosto, 2014.

República Democrática del Congo v. Bélgica (2001): CIJ, 14 de febrero de 2002 (caso sobre la Orden de Arresto de 11 de abril de 2000, párr. 61).

Re Honecker (1984): Tribunal Supremo Federal, Segunda Sala de lo Penal (República Federal de Alemania), sentencia de 14 de diciembre de 1984.

Sam Fang and Others v. Zemin Jiang and others (2006): High Court de Nueva Zelanda, 21 de diciembre de 2006.

Tachiona v. Mugabe (“Tachiona I”) (2001): Tribunal de Distrito de Nueva York (Estados Unidos), sentencia de 30 de octubre de 2001.

$X v$. État allemand (2002): Corte de Apelación de Paris, 9 de septiembre de 2002.

W. v. Prince of Liechtenstein (2001): Tribunal Supremo (Austria), sentencia de 14 de febrero de 2001.

\section{DOCUMENTO EN FORMATO ELECTRÓNICO}

Chetail, Vincent (2003): "La contribución de la Corte Internacional de Justicia al derecho internacional humanitario”. Disponible en: https://www.icrc.org/spa/resources/documents/misc/5uamwj.htm

\section{NORMAS CITADAS}

España. Ley Orgánica $N^{\circ} 1$ del 13 de marzo de 2014.

España. Ley Orgánica Nº de 1985. 
